\title{
Article \\ Contrasting Patterns of Sensory Adaptation in Living and Extinct Flightless Birds
}

\author{
Peter Johnston ${ }^{1, *(1)}$ and Kieren J. Mitchell ${ }^{2}$ (D) \\ 1 Department of Anatomy and Medical Imaging, University of Auckland, P.O. Box 92019, \\ Auckland 1142, New Zealand \\ 2 Department of Zoology, University of Otago, 340 Great King Street, Dunedin 9054, New Zealand; \\ kieren.mitchell@otago.ac.nz \\ * Correspondence: petersjohnston54@gmail.com
}

check for updates

Citation: Johnston, P.; Mitchell, K.J. Contrasting Patterns of Sensory Adaptation in Living and Extinct Flightless Birds. Diversity 2021, 13, 538. https://doi.org/10.3390/ d13110538

Academic Editors: Eric Buffetaut and Delphine Angst

Received: 1 October 2021

Accepted: 22 October 2021

Published: 26 October 2021

Publisher's Note: MDPI stays neutral with regard to jurisdictional claims in published maps and institutional affiliations.

Copyright: (C) 2021 by the authors. Licensee MDPI, Basel, Switzerland. This article is an open access article distributed under the terms and conditions of the Creative Commons Attribution (CC BY) license (https:// creativecommons.org/licenses/by/ $4.0 /)$.

\begin{abstract}
Avian cranial anatomy is constrained by the competing (or complementary) requirements and costs of various facial, muscular, sensory, and central neural structures. However, these constraints may operate differently in flighted versus flightless birds. We investigated cranial sense organ morphology in four lineages of flightless birds: kiwi (Apteryx), the Kakapo (Strigops habroptilus), and the extinct moa (Dinornithiformes) from New Zealand; and the extinct elephant birds from Madagascar (Aepyornithidae). Scleral ring and eye measurements suggest that the Upland Moa (Megalapteryx didinus) was diurnal, while measurements for the Kakapo are consistent with nocturnality. Kiwi are olfactory specialists, though here we postulate that retronasal olfaction is the dominant olfactory route in this lineage. We suggest that the Upland Moa and aepyornithids were also olfactory specialists; the former additionally displaying prominent bill tip sensory organs implicated in mechanoreception. Finally, the relative size of the endosseous cochlear duct revealed that the Upland Moa had a well-developed hearing sensitivity range, while the sensitivity of the kiwi, Kakapo, and aepyornithids was diminished. Together, our results reveal contrasting sensory strategies among extant and extinct flightless birds. More detailed characterisation of sensory capacities and cranial anatomy in extant birds may refine our ability to make accurate inferences about the sensory capacities of fossil taxa.
\end{abstract}

Keywords: moa; Aepyornis; kiwi; kakapo; olfaction; vision; hearing

\section{Introduction}

The concept of the complementary use of avian senses-and trade-offs among themprovides a framework for the inference of sensory function and sensory ecology in both living and extinct taxa [1]. Indeed, there has been increasing interest recently in 'avian palaeoneurology' - the inference of sensory and other function from the shape of the brain as a whole and from brain components related to specific functions [2], particularly for fossil taxa (e.g., [3,4]). However, the power of these inferences is limited by our incomplete understanding of the complex links between avian cranial anatomy and function. Of particular importance for improving our understanding are flightless birds, many of which appear to have evolved unusual combinations of sensory capacities. Detailed study of the sensory structures of flightless birds-both living and extinct-may therefore help to illuminate the full diversity of possible avian sensory patterns, and the trade-offs involved in their evolution.

Flightlessness has evolved multiple times in the ancestors of a number of bird species from New Zealand (NZ), including a large, flightless, nocturnal parrot-the Kakapo (Strigops habroptilus). In addition, two lineages of flightless palaeognathous birds evolved in New Zealand-the extant kiwi (Apteryx) and the recently extinct moa (Dinornithiformes). Molecular phylogenetic work has revealed that kiwi and moa are only distant relatives [5-8], with the kiwi being the sister group of the extinct elephant birds (Aeyornithidae) from 
Madagascar, and moa the sister group of tinamous from South America (Figure 1A). Based on the phylogeny and distribution of these lineages, it is argued that the ancestors of the kiwi, moa, and elephant birds all independently evolved flightlessness (and any concomitant sensory specialisations). In this study, we explore the sensory anatomy of representatives from these four lineages of flightless avians-kiwi, the Kakapo, moa, and elephant birds - with a view to better characterising their patterns of sensory use and specialisation.
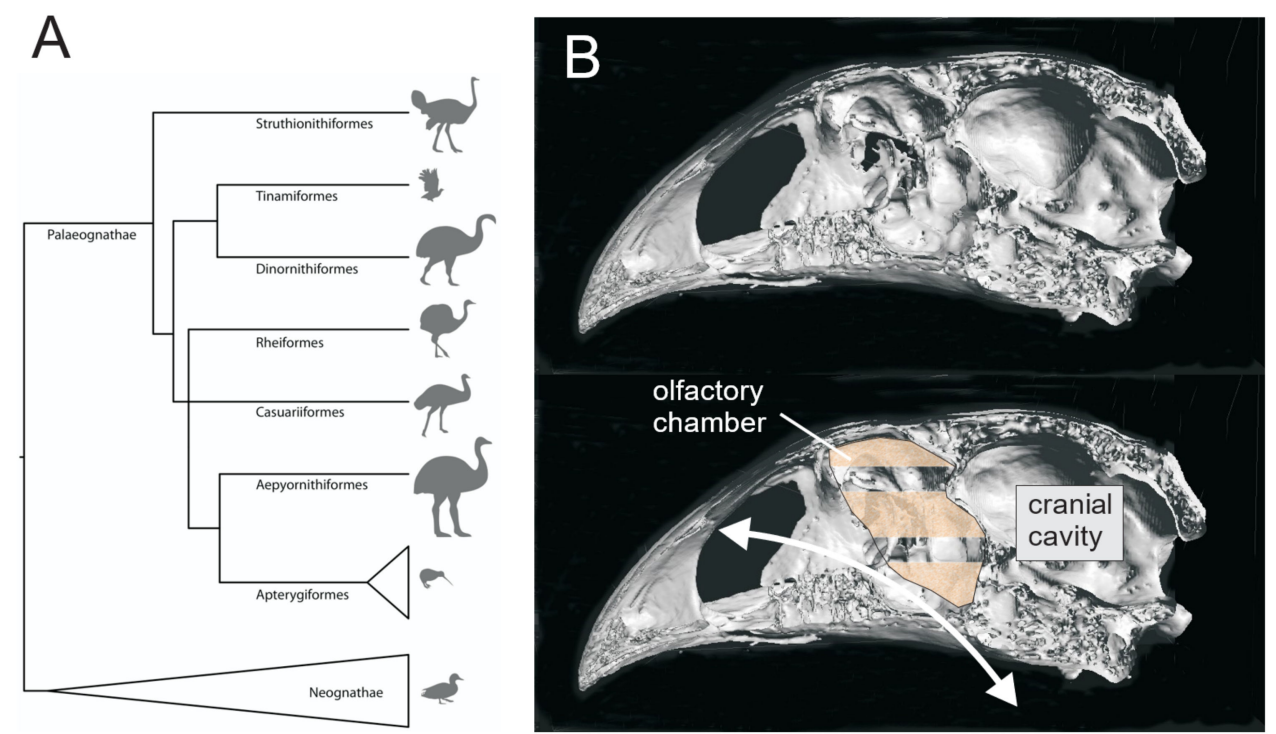

Figure 1. (A) phylogenetic tree indicating relationships of palaeognathous birds. (B) Pachyornis elephantopus, mid-sagittal skull reconstruction, showing nasal air passage (arrow), olfactory chamber, and cranial cavity.

Kakapo have previously been studied in detail in relation to their sensory capabilities and adaptations to nocturnality [9]: enhanced light sensitivity, reduced visual acuity, a wide binocular visual field, and reliance on olfaction. Similarly, the sensory capabilities of kiwi are well known, having a nocturnal lifestyle, very limited vision, enhanced olfaction, and mechanoreceptive function at the tip of the bill and vibrissae at the base of the bill [10-12]. The anatomy of the kiwi olfactory system has also been described in detail at the level of neurological morphology and fine structure of the olfactory mucosa [12], and of the air passages and complex caudal turbinate scroll [13], but the mechanics of airflow in the nasal passages is less clear. The external nares of kiwi are placed at the tip of the bill, unique among avians, and a complex turbinate system, similar to that of mammalian rodents, lies adjacent to the rostral end of the brain in a greatly expanded interorbital septum. The olfactory behaviour of kiwi is described as poking the bill into the substrate, olfactory search with a raised bill arcing around the direction of search [10], and frequent loud 'sniffing'. It is not clear, however, if sniffing, a typical mammalian behaviour, is possible in the low-pressure respiratory system of birds, and it is also unclear whether the very small external nares of kiwi are effective for air entry. In contrast to Kakapo and kiwi, very little is known about the biology of elephant birds [14]: small eyes were a feature, and inferences from endocasts suggest a reduced reliance on vision [4]; herbivorous diet and evolution in a predator-free environment are assumed.

The sensory capabilities of moa are also uncertain and remain debated. Moa eye size is relatively small, and the interorbital septum is expanded by a large chamber in continuity with the nasal air passage [15] — this has been regarded as an olfactory chamber since the earliest accounts of moa anatomy [16,17] — and the bony turbinate system is moderately elaborated [15]. In examinations of moa brain endocast morphology [18,19], however, the olfactory bulb at the rostral end of the forebrain was found to be within the range of extant palaeognaths (kiwi excepted), with olfactory bulb size being regarded as a surrogate 
for olfactory ability $[20,21]$. It was thus concluded that moa had an 'apparently poor advanced olfactory capacity', and suggested that the 'olfactory chamber' was a resonating chamber for vocal behaviour [18]. Indeed, it had earlier been suggested on the basis of the flora thought to have been eaten by moa that they had excellent visual acuity and poor olfaction [22]. In contrast, it was instead postulated that the olfactory lobe of the brain had been absorbed into the bulk of the telencephalon as a response to local space constraints, and was-in fact-much larger than the structure identifiable at the rostral end of the brain [23]. Subsequently, the substantial absorption of the olfactory lobe into the telencephalon in kiwi was confirmed [12], leaving open the possibility that the same is true for moa, while questions of relatively poor vision and nocturnality in moa have recently been raised on the basis of the very small optic lobes of the midbrain in two moa species $[3,4]$. The sensory ecology of moa thus remains unresolved.

Here we present new findings that add to existing evidence on sensory function in flightless bird taxa, focusing on olfaction, vision, and hearing, and consider how these senses may be integrated. We focus on these four taxa-moa, kiwi, elephant birds, and Kakapo as they form or are parts of island radiations on New Zealand and Madagascar, and we can make comparisons among them with the analytical methods and new data that we present. The data on moa concentrate on one species, the Upland Moa (Megalapteryx didinus), for which we have the most complete information. We also present new measurements from an elephant bird (Aepyornis maximus), Chilean Tinamou (Nothoprocta perdicardia), American Rhea (Rhea americana), Kakapo (S. habroptilus), and Southern Brown Kiwi (Apteryx australis).

\section{Materials and Methods}

\subsection{Materials}

A list of material examined is given in Appendix A.

\subsection{Moa}

Moa osteology material was examined with particular focus on incomplete and broken skulls that revealed the olfactory chamber and foramina between the cranial cavity and olfactory chamber. A head of $M$. didinis with attached mummified soft tissue (MNZ S400) [24] includes a complete scleral ring in several fragments, loosely held together for parts of the circumference by soft tissue, currently preserved in alcohol. This is one of three known moa specimens with intact scleral ossicles [25]. An MRI scan of this moa specimen was obtained as documented previously [26], and dimensions of the orbit obtained from this.

\subsection{Kiwi}

Skulls of kiwi were examined, again with focus on broken material that reveals the internal structure of the olfactory passages. CT and MRI scans of kiwi heads were used to reconstruct brain and olfactory passages. A serial sectioned hatchling kiwi head was used to define details of the nasal glands. Newly deceased kiwi obtained as road-kill were obtained under permit from the Department of Conservation, New Zealand, for dissection.

\section{Computational Fluid Dynamics (CFD)}

Simulations were performed using a 3D reconstruction of the nasal and olfactory passages in Apteryx (AMNH18456) from segmentation on axial CT slices for CFD simulation in Simscale [27]. The resulting mesh with its intricate internal geometry was too complex for simulations after multiple simplifications, so a mesh was built to the same external dimensions with Meshmixer [28] and openings made at appropriate sizes and positions of external and internal nares. Simulations were run with the following assumptions: incompressible medium, air in standard conditions as the fluid medium, Newtonian viscosity model, and standard meshing algorithm. Pressure differences between external and internal nares were set at 100 Pascals $(\mathrm{Pa})$, within the physiological pressure range for 
quiet breathing in avians [29]. Kiwi respiratory rate is about 30 breaths per minute [30], so simulations of orthonasal and retronasal flow were captured at $10 \mathrm{~s}$ intervals up to $40 \mathrm{~s}$. Other parameters for fluid dynamics including the Reynolds number are calculated by the software on the basis of the size of the model and the input and output values (pressures in this case). Simulation results were visualised with the particle trace algorithm of Simscale.

\subsection{Comparative Material}

Skulls of all palaeognaths apart from tinamous were examined, together with a range of neognaths. Cranial CT scans of all genera of ratites and three genera of tinamous were surveyed, and about $400 \mathrm{CT}$ scans of neognaths available at online resources [31-34] were reviewed with focus on the interorbital septum and olfactory nerve passages. Kakapo morphology was studied on 3D skull mesh reconstructions and high-resolution CT scan images. Neognaths with known superior olfactory capability $[13,20]$ were specifically sought in these collections, in particular vultures and Procellariiformes.

\subsection{Observation of Living Kiwi}

Stewart Island Brown Kiwi (Southern Tokoeka) Apteryx australis lawryi were observed foraging at Mason Bay, Stewart Island Rakiura, New Zealand. Kiwi in this locality forage by day as well as the typical nocturnal activity.

\subsection{Compliance Statement}

Use of all specimens conformed to NZ Department of Conservation regulations and permits, and to CITES conventions.

\subsection{Analyses}

\subsubsection{Vision}

Visual fields in M. didinus were estimated in Blender [35] by loading a mesh of the skull from a 3D CT reconstruction. A virtual $360^{\circ}$ light was placed in the expected position of the cornea, and the emitted light projected onto a spherical mesh.

Inference of daily activity pattern (nocturnal versus non-nocturnal) was estimated with measurements of scleral ring and orbit dimensions. An 'optic ratio' of (internal scleral ring diameter $)^{2} /$ (optic length $\mathrm{x}$ external ring diameter) was plotted against the geometric mean of these three measurements according to the method of [36] and added to the data of that study, for a total of 370 taxa, to place birds in nocturnal and diurnal bands (Table S1). A 'flexible phylogenetic discriminant analysis' (fPDA) [37] to derive a posterior probability of nocturnality was done using the method and $R$ codes of [36]. An earlier version of this analysis [37] which adds axial length of the eye to the formula: (log lens diameter) ${ }^{2}$ plotted against $\log$ (external scleral ring diameter $\mathrm{x}$ axial eye length) was also calculated. These analyses were performed for M. didinus and S. habroptilus.

\subsubsection{Hearing}

The length of the endosseous cochlear duct (lagena) (ECD) of the inner ear was measured on inner ear labyrinths reconstructed from CT series in M. didinus, Aepyornis maximus, Rhea americana and Nothoprocta pericardia. Measurements were made in 3D in Amira, with the axis of measurement lying within the structure. Maximal cranial height over the basisphenoid was measured also. Data were added to the data set of [36] (Table S2) and used for regression of ( $\log 10$ ECD length) against (log10 braincase height) using the method and R codes of [36]. A phylogenetic regression was performed using the gls function of nlme [38] allowing $\lambda$ to be fitted using the corPagel function of ape [39] using $\mathrm{R}$ version v4.0.1 in RStudio v1.4.1717. Residuals from this regression were used as an index of hearing ability, as verified previously [40] and were plotted against phylogeny. 


\subsection{Phylogenetic Trees}

Estimating $\lambda$ requires a phylogeny to correct for correlation due to shared ancestry. Most previous studies, including [36] have used supertrees derived from studies by [41] or [42]. However, these trees are unsuitable for our purposes because they all support the reciprocal monophyly of Tinamiformes and the other palaeognaths-which has since been definitively rejected (e.g., $[7,8])$.They also do not include representatives of the extinct Aepyornithiformes or Dinornithiformes. Since our expanded ECD matrix includes the moa M. didinus, elephant bird Ae. maximus, and tinamou N. pericardia, we needed updated phylogenetic reconstructions that accurately reflected the relationships of these taxa in order to estimated $\lambda$.

We constructed phylogenetic trees based on an alignment of published mitochondrial DNA sequences (Table S3). Where available, we downloaded complete mitochondrial genome sequences for the 92 species represented in the ECD matrix. Where mitochondrial genome sequences were not available we either used those of a close relative and/or sequences for only a subset of mitochondrial genes (Table S3). These sequences were aligned using the MUSCLE v3.8.425 [43] algorithm as implemented in Geneious v9.1.6 [44]. We then extracted-where available - the first and second codon positions of the 12 mitochondrial protein coding genes encoded on the leading strand for downstream analysis; third codon positions were excluded to avoid branch compression and other artifacts caused by substitution saturation.

Time-scaled phylogenetic trees were constructed using BEAST v1.8.4 [45]. First and second codon positions were analysed as separate partitions using substitution modelsGTR + I + G and TVM + I + G, respectively-determined using ModelFinder as implemented in IQ-TREE v1.6.11 [46,47]. The monophyly of several higher taxa was enforced to match the phylogenomic results published by [48] (see Table S1). Following [6] we calibrated our phylogeny by constraining the age of six nodes: the common ancestor of Neoaves (uniform distribution between 66.5 Ma and 124.1 Ma), the common ancestor of Galloanseres (uniform distribution between 66.5 MA and 83.8 Ma), the divergence of Psittaciformes (uniform distribution between 53.5 Ma and 72.3 Ma), the divergence of Procellariformes (uniform distribution between 60.5 Ma and 72.3 Ma), the common ancestor of all non-ostrich palaeognaths (uniform distribution between 56.0 Ma and 72.3 Ma), and the divergence of Casuarius (uniform distribution between 24.5 Ma and 72.3 Ma).

We ran three separate BEAST analyses that were identical except that in each analysis we constrained the relationships between three palaeognath lineages-Rhea, Casuarius, and a clade comprising Apteryx and Aepyornis - to match one of the three possible topologies: Rhea \& Casuarius as sister taxa, Casuarius as the sister-taxon to Apteryx + Aepyornis, and Rhea as the sister-taxon to Apteryx + Aepyornis. We did this to test the sensitivity of our downstream results to the order of these divergences, which are not well resolved [49]. For each of these three analyses we performed seven separate Markov Chain Monte Carlo (MCMC) runs. All BEAST analyses used a single lognormal relaxed clock model (with rate multipliers for the two partitions) and a birth-death tree prior. Each MCMC was run for 20,000,000 generations, sampling parameter values every 2000 . The first $10 \%$ of each chain (1000 samples) was discarded as burn-in, and the remaining 63,000 samples for each analysis were combined. Convergence of parameter values and ESSs $>200$ were monitored using Tracer v1.7.1 [50]. From each analysis we randomly selected a sample of 100 representative trees to use for estimating $\lambda$. We also estimated $\lambda$ using a combined sample of all 300 trees, thus averaging across the uncertainty around the branching order among Rhea, Casuarius, and the clade comprising Apteryx and Aepyornis.

\section{Results}

\subsection{Olfaction}

\subsubsection{Moa}

The large olfactory chamber and its relation to the cranial cavity and the airway in Pachyornis elephantopus is demonstrated in Figure 1B. A complex olfactory nerve exit from 
the cranium is found in all moa, no adult birds having a single nerve trunk. Multiple nerve branches, as many as 15 , penetrate the bony interface between cranium and olfactory chamber, resembling the cribriform plate of mammals; there is variation among individuals and between right and left sides, and typically a small bony mound is seen on the olfactory chamber side of this plate with multiple foramina penetrating and surrounding it (Figure 2C,D). The inner walls of the posterior part of the chamber are grooved by nerve branches radiating from the foramina (Figure 2C,D). This can be seen also in CT scans, and a reconstruction of the proximal nerve branching is shown in Dinornis robustus in Figure 2E. In juvenile moa a separate central bone element is found that represents the most caudal part of the olfactory chamber [15] (Figure 2A,B). This an open box-like structure that is entered by large olfactory nerve foramina caudally, has a median septum, and opens rostrally to the rest of the olfactory chamber.
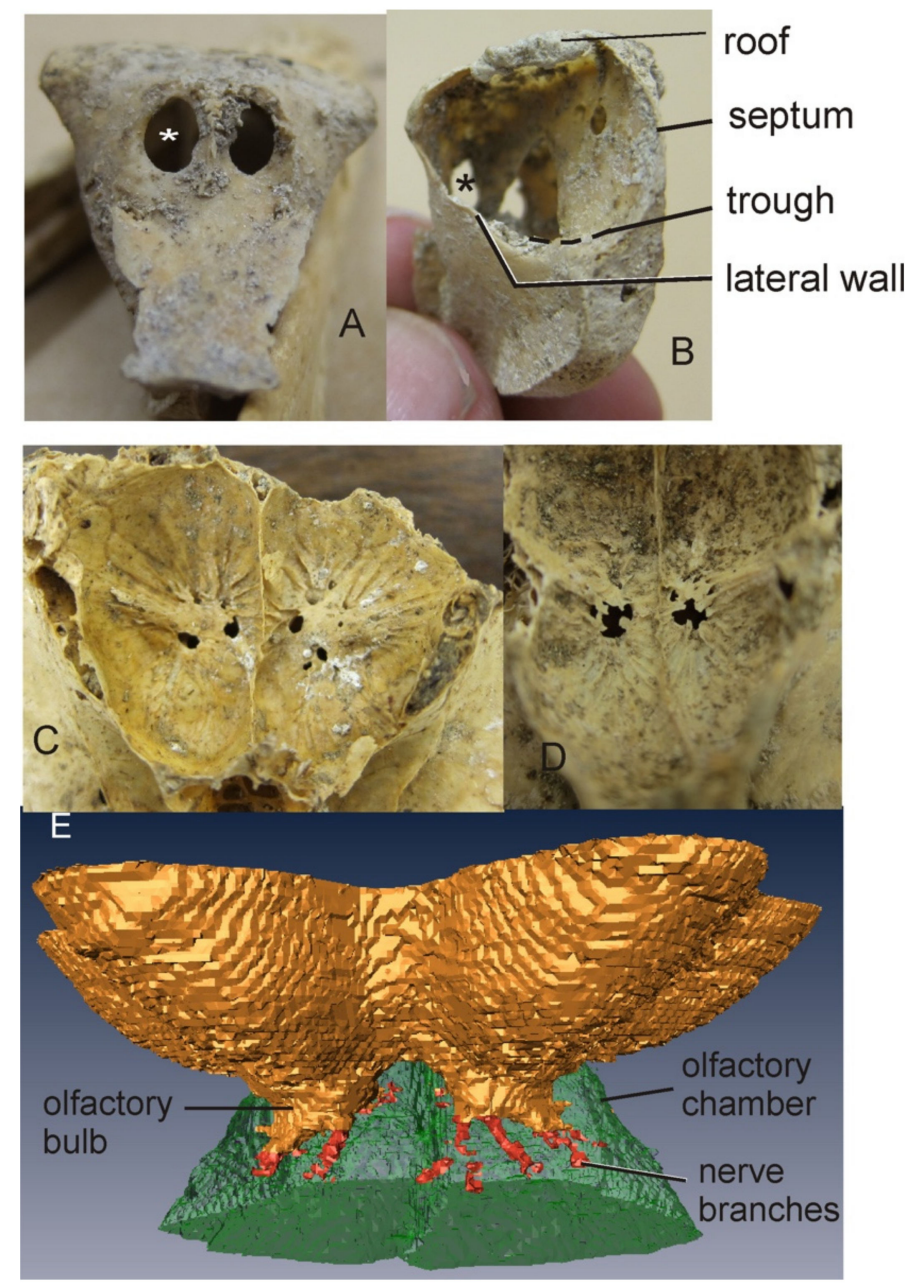

Figure 2. Moa olfactory foramina. (A) juvenile Anomalopteryx didiformis, ethmoid ossification, caudal view. (B) right rostrolateral view. * marks the foramen $(\mathbf{C})$ A. didiformis, rostral view of foramina with radiating nerve grooves; (D) Dinornis novaezealandiae, same view. (E) Dinornis robustus, reconstruction of interface brain-olfactory chamber dorsal view.

\subsubsection{Kiwi}

The external nares in specimens with an intact rhamphotheca admit a wire of $0.6 \mathrm{~mm}$ diameter (Figure $3 \mathrm{~A}$ ), giving a cross-section area of $0.28 \mathrm{~mm}^{2}$. The internal nares Figure 3B are formed by longitudinal ellipses of area $9.42 \mathrm{~mm}^{2}$ in adult birds. The complex turbinate system and its relation to the forebrain are shown in Figure 4. 


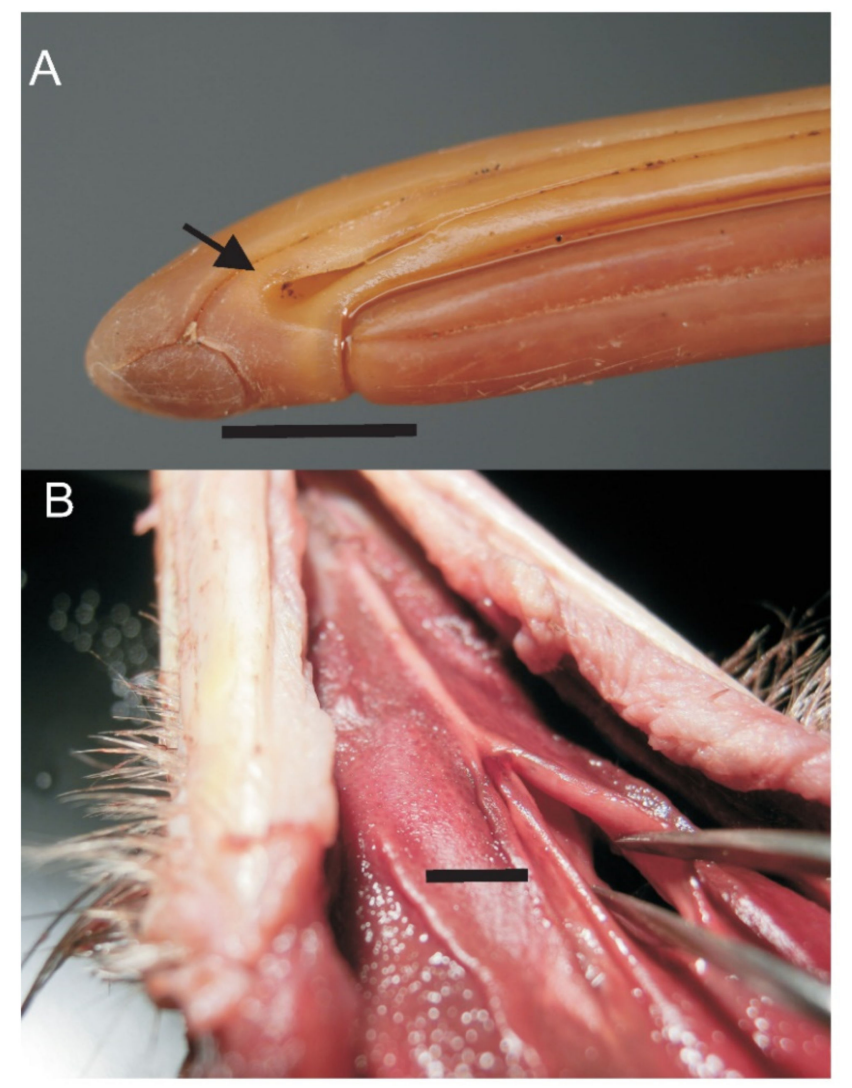

Figure 3. Apteryx mantelli. (A) external nares (arrow) (B) internal nares (in forceps). Scale bars $=1 \mathrm{~cm}$.

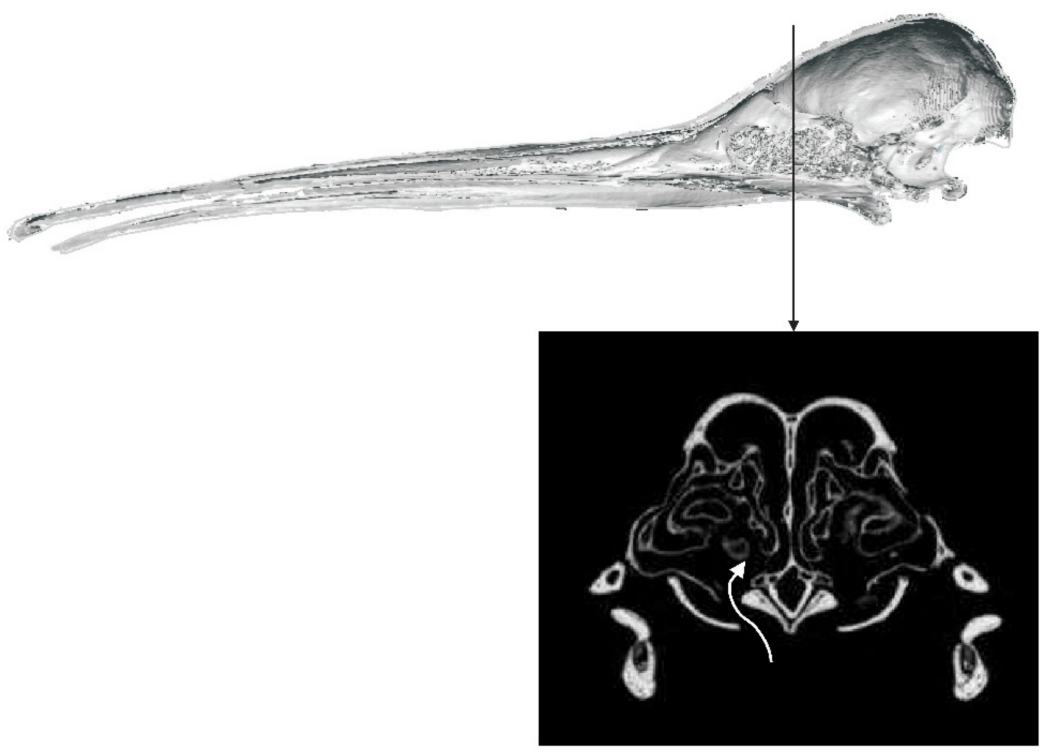

Figure 4. Apteryx, CT scan slice at the level of internal nares and turbinate system. The arrow indicates the route through the nares to the olfactory region.

CFD simulations revealed very little flow into the olfactory airways with orthonasal flow under the physiological pressures used. Simulation of retronasal olfaction showed airflow to around the olfactory chamber and nasal airway at all $10 \mathrm{~s}$ iterations (Figure 5). With the simulation process used here, when air velocity is very low or zero a particle trace is not generated. With retronasal aeration, vectors of flow are consistent with a retronasal route as the dominant mode of olfaction in kiwi. 


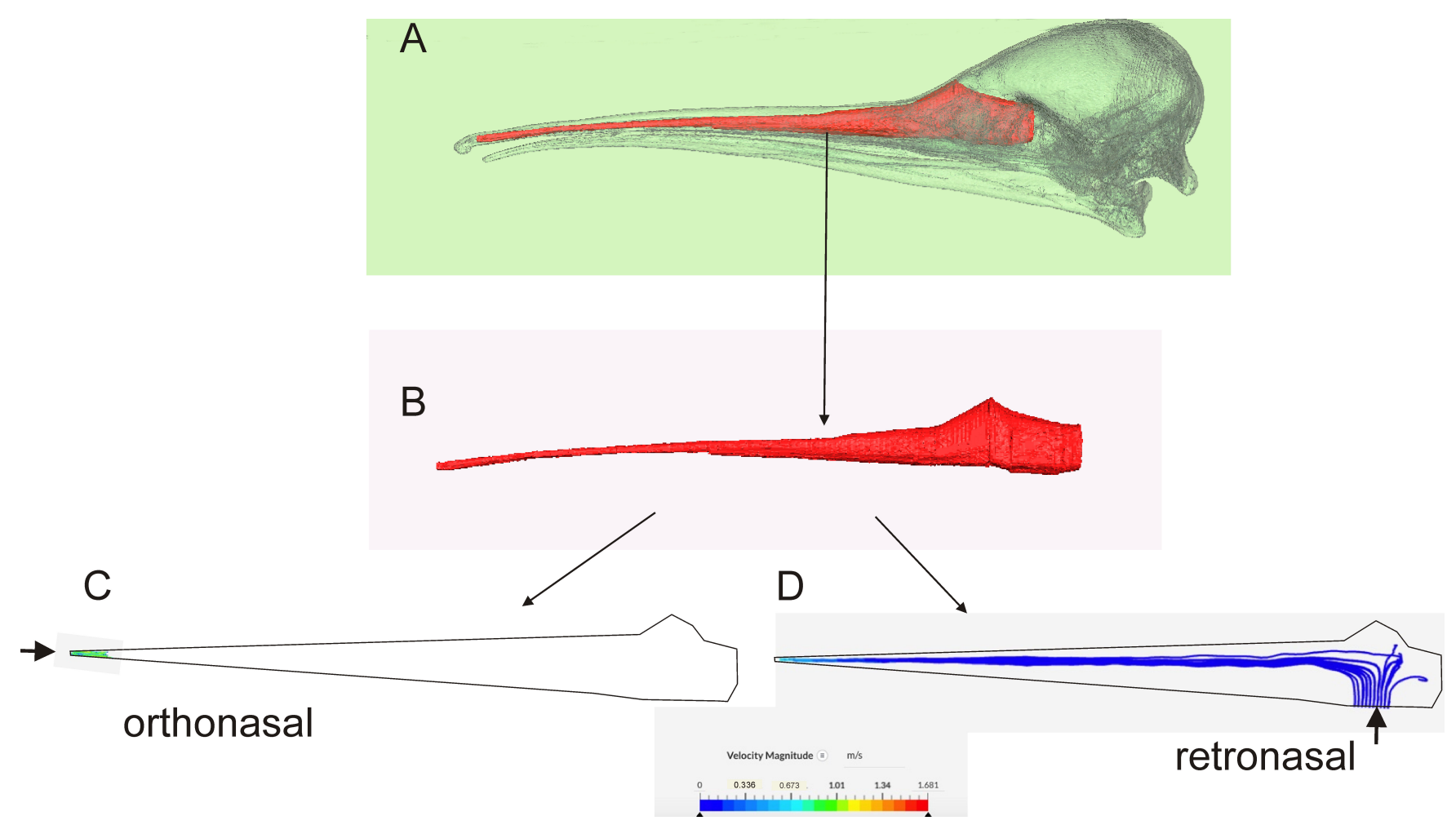

Figure 5. Computational flow dynamics; nasal cavity (A) in situ (B) isolated (C) and (D), flow simulations.

Wild kiwi were observed to make snuffling or snorting respiratory noises while foraging, accompanied by head movements as previously described [10]; it was not determined whether these were inspiratory or expiratory noises except on occasions when bubbles appeared at the nares, which was clearly an expiratory phenomenon.

In histological sections the nasal glands of Apteryx are situated in a conventional position on the dorso-lateral aspect of the maxilla, immediately rostral to the orbit. Medial and lateral ducts lead forward on either side of the conchal system to reach the vestibule of the nasal passage immediately adjacent to the external naris. Uncommonly for birds [51], the right and left medial ducts converge to form a single duct at the ventral edge of the septum for the rostral two-thirds of the bill, before dividing again close to the naris. The large lacrimal gland duct passes rostrally parallel and ventral to the lateral nasal gland duct, again opening into the vestibule adjacent to that duct. Thus, all three ducts enter adjacent to the naris.

\subsubsection{Aepyornithidae}

In Aepyornis maximus and Ae. hildebrandti the forebrain and the olfactory chamber occupy the dorsal third of the space between the eyes; the extent of the chamber is indicated in Figure 6A. The caudal end of the chamber is grooved by radiating olfactory nerve branches in a pattern similar to that of moa (Figure 6B).

\subsection{Vision}

\subsubsection{Moa}

The analysis of eye dimensions in M. didinus using the method of [36] place it within the band of non-nocturnal birds (Figure 7A). The posterior probability of non-nocturnal state calculated by the fPDA is above $99 \%$ with all values of lambda (an optimal lambda of 0.07 was obtained). In the predictive plot of [37], M. didinus falls among cathemeral birds (Figure 7B). Visual fields estimated for M. didinus are shown in Figure 8. They reveal a small binocular field, and a large blind sector caudally. 


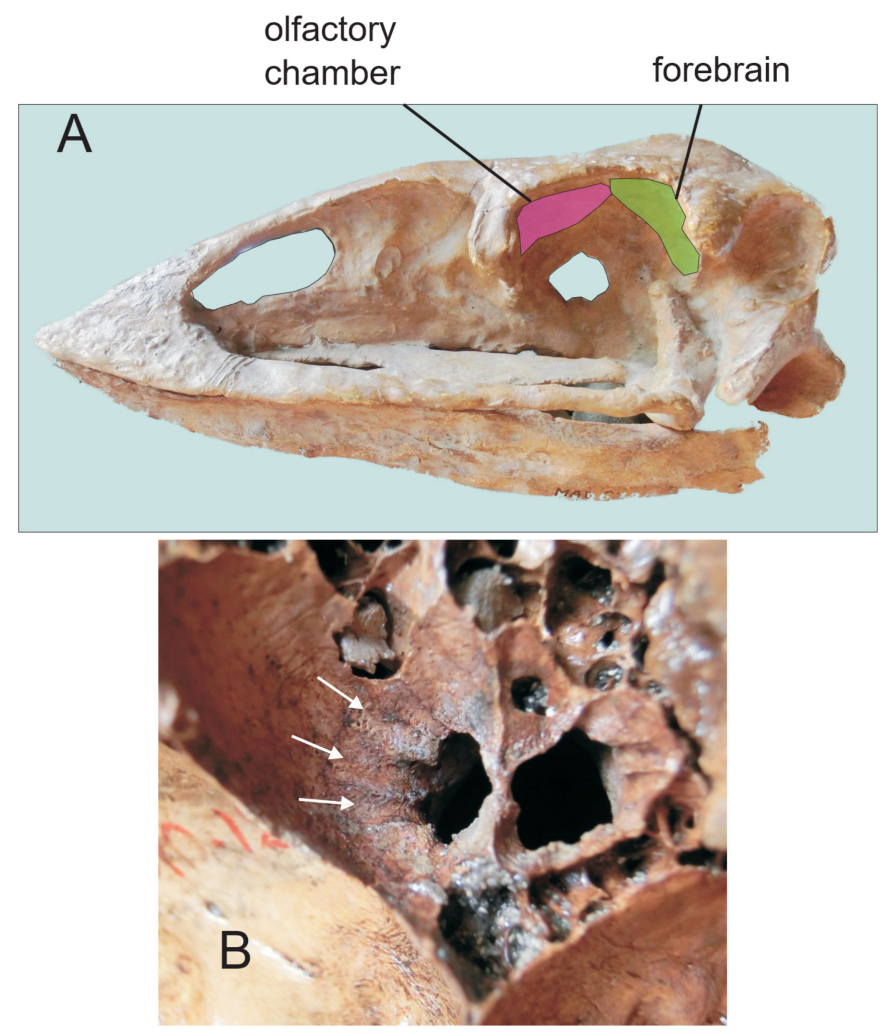

Figure 6. (A) Aepyornis ?hildebrandti, MNHN MAD6724 olfactory chamber and forebrain outlined (B) Aepyornis maximus MNHN 1910.12, rostral view of olfactory formaina with radiating nerve grooves (arrows).
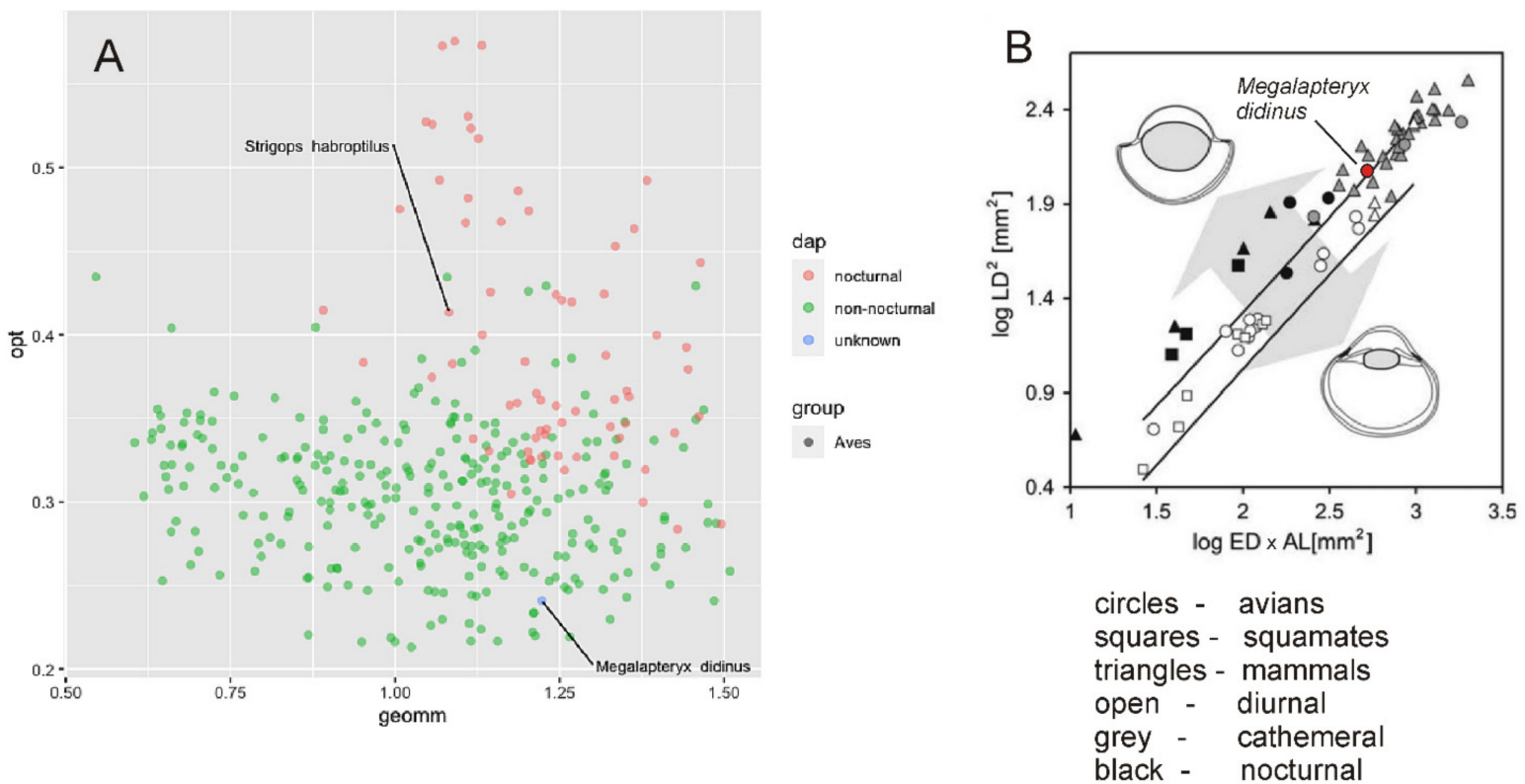

(LD, lens diameter, ED eye diameter $A L$, axial eye length)

Figure 7. (A) plot of optic ratio (opt) against geometric mean of eye measurements (geomm). dap,daily activity pattern. (B) plot reproduced with permission from [37], with Megalapteryx didinus added. 

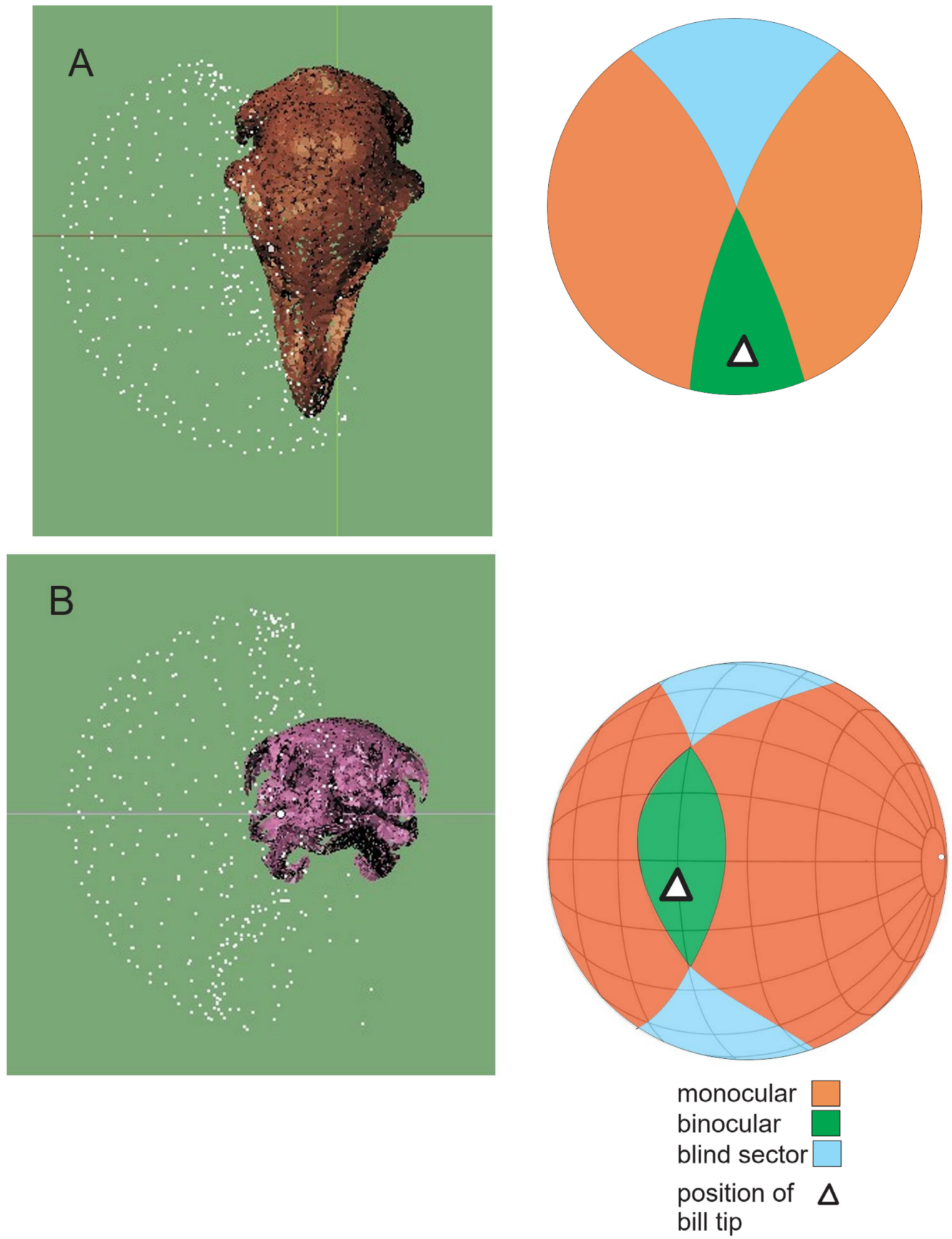

Figure 8. Megalapteryx didinus, visual field plot, as reconstructed and graphically after the convention of Martin [1], in (A) dorsal and (B) frontal views.

\subsubsection{Kakapo}

In the analysis framework used, S. habroptilus, known to be nocturnal but with other parameters of eye anatomy deemed not typical for either diurnal or nocturnal activity [9], falls at the overlap zone in the plot but receives a probability of nocturnality of 0.68 .

\subsection{Hearing}

Residuals of ECD against cranial height in phylogenetic generalised least squares regression are plotted against our phylogeny in Figure 9. A number of interesting results appear: M.didinus had the largest spectrum of hearing frequencies of any palaeognath, while Aepyornis was at the lower end of the group of birds sampled. Apteryx and Strigops 
are both placed as birds with limited frequency hearing. This result for Strigops is also shown in [36] within the phylogeny of that study, but is not commented on.
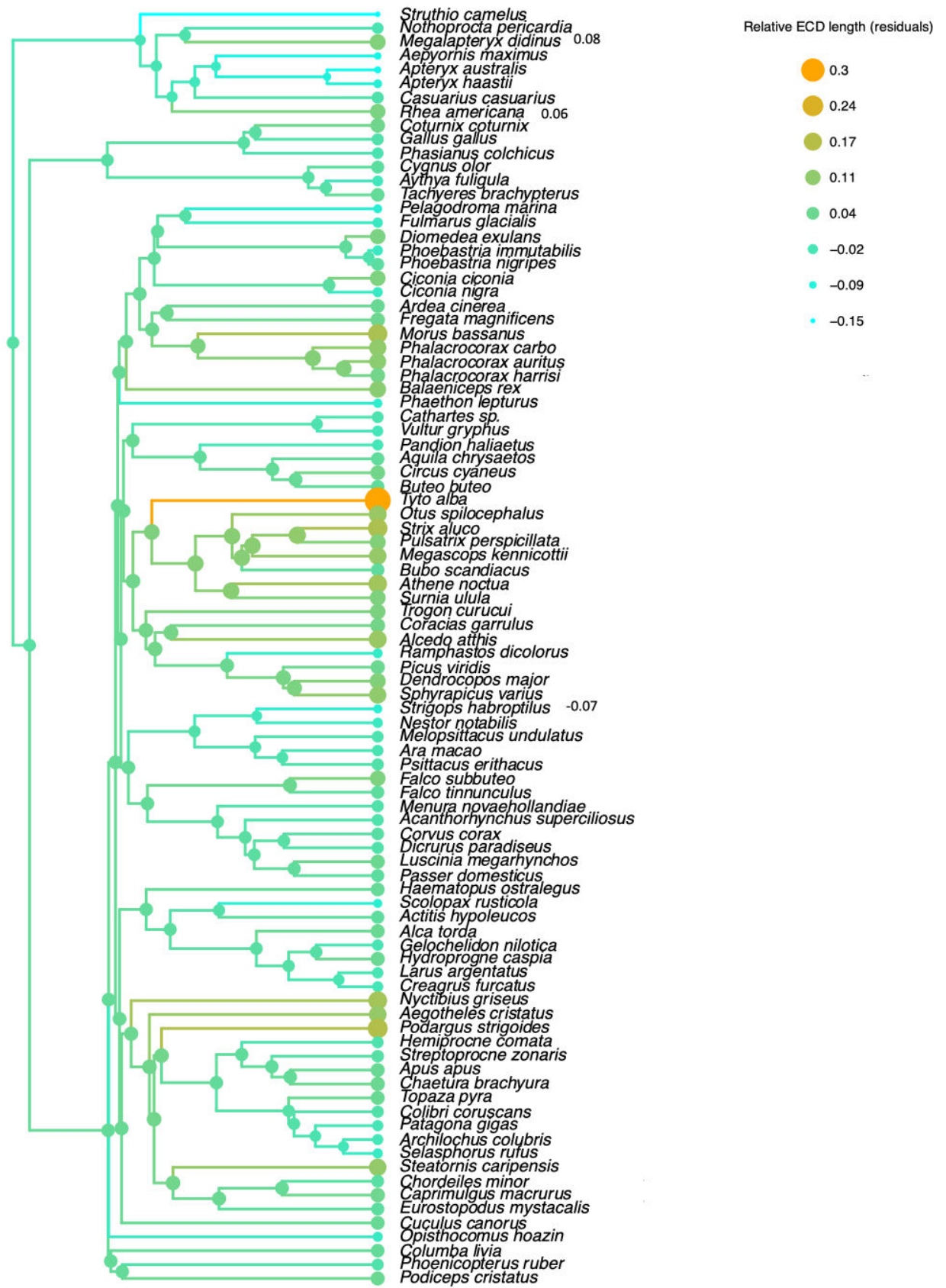

Figure 9. Endosseous cochlear duct residuals plotted to phylogeny (residual values added against taxa of interest).

The inner ear labyrinth of M. didinus is shown in Figure 10A. This also demonstrates the cerebellar flocculus, or more accurately, the endocast of the floccular fossa [52]. M. didinus has a qualitatively substantial floccular endocast.

\subsection{Bill Tip Sensory Organs}

Specialised mechanoreceptors known as Herbst corpuscles are found in bony pits in the bill tips of extant palaeogaths and a variety of neognaths that use bill-probing behaviour. Pits are present in all moa species; in Megalapteryx, they are most prominent on the oral aspect of the premaxilla (Figure 10B). The trigeminal ganglion endocast in Megalapteryx 
appears prominent, more so than in figures of other palaeognaths [4], and the ophthalmic division of the trigeminal nerve $\left(\mathrm{V}_{1}\right)$ is also relatively large, qualitatively (Figure 10C,D).
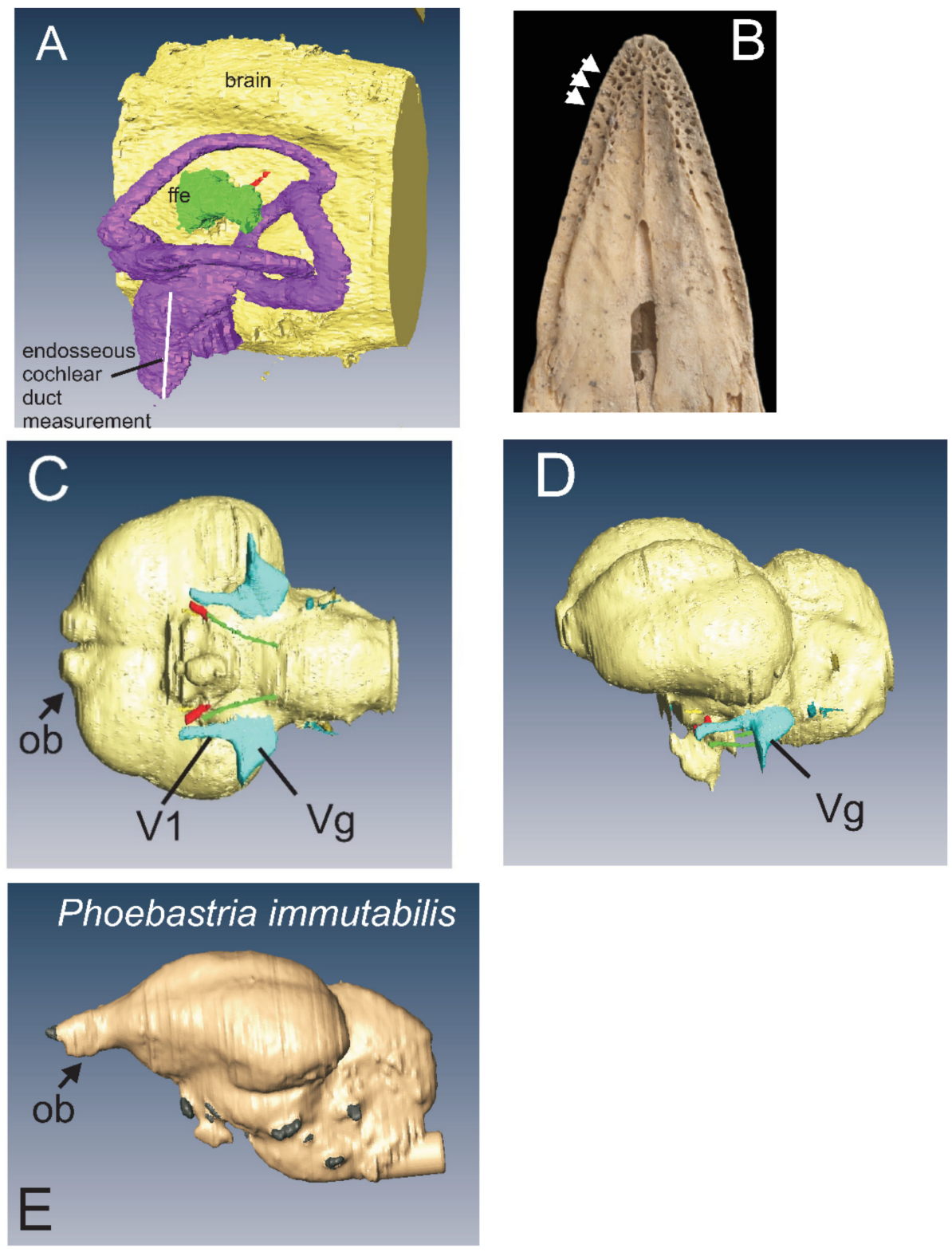

Figure 10. (A) Megalapteryx didinus left otic labyrinth and adjacent structures. ffe, floccular fossa endocast (B) M. didinus, bill pits in oral view, photo courtesy of Trevor Worthy (C,D) M. didinus, brain reconstruction in (C) ventral and (D) left lateral views.ob, olfactory bulb, V1, ophthalmic division trigeminal nerve; $\mathrm{Vg}$, trigeminal ganglion (E) An albatross with a well-developed olfactory bulb.

\subsection{Comparative Material}

3.5.1. Palaeognathae

A small dorsal olfactory chamber is present in non-NZ ratites, directly in contact with the cranial cavity with a very short olfactory nerve trunk in Struthio, Dromaeus, and Casuarius, and with an olfactory nerve that traverses the orbital cavity for $1.5 \mathrm{~cm}$ in Rhea. A substantial mono-laminar septum is present ventral to this dorsal chamber in these taxa. Tinamous have a single nerve that traverses the orbit for the whole length of the interorbital septum. A substantial mono-laminar septum is present ventral to this dorsal chamber in these taxa. 


\subsubsection{Neognathae}

In neognaths, there are two principal patterns: a small, dorsal olfactory chamber above a mono-laminar septum, and a complete mono-laminar septum. Some species with known olfactory ability $[13,20]$ have marked expansion of the septum by an olfactory chamber, notably in vultures and Procellariiformes. The Turkey Vulture Cathartes aura is known for olfactory specialisation, and in this taxon, the whole of the interorbital septum is expanded by a broad olfactory chamber, part of which contains the scrolled caudal concha (Figure 11A). This configuration of olfactory chamber is very similar to that of moa. The Black Vulture Coragyps atratus are closely related to the Turkey Vulture and have above average olfaction in terms of the numbers of mitral cells in the olfactory bulb [53], but still reduced in comparison to Cathartes aura. The interorbital septum is again expanded by an olfactory chamber (Figure 11B), but to a lesser degree than in Cathartes. Among other birds, an extensive olfactory chamber filling much of the interorbital septum is seen in the olfactory specialists Puffinus grisea, Pachyptila desolata, Thalassarche chlororhynchus, Fulmaris glacialis, and Pagodroma nivea. In the many CT series reviewed, marked expansion of the dorsal septum or any expansion of the ventral part of the septum was only seen in taxa such as the above with known olfactory specialisation.

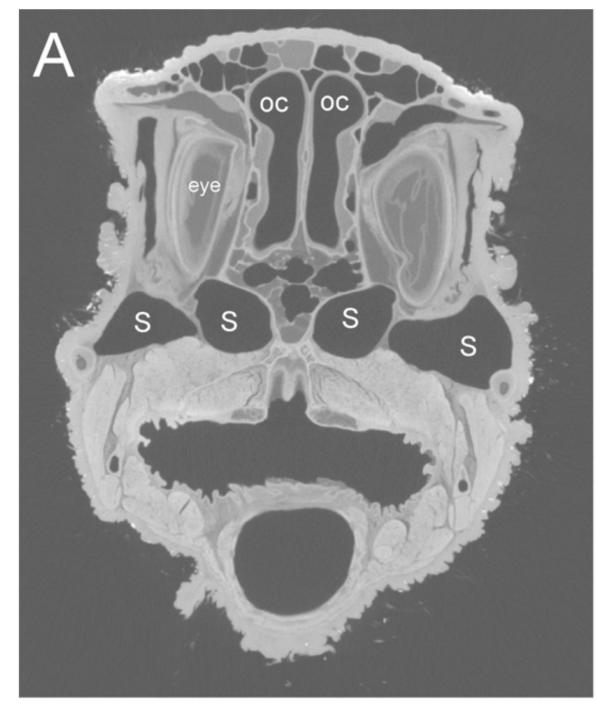

Cathartes aura (Turkey Vulture)

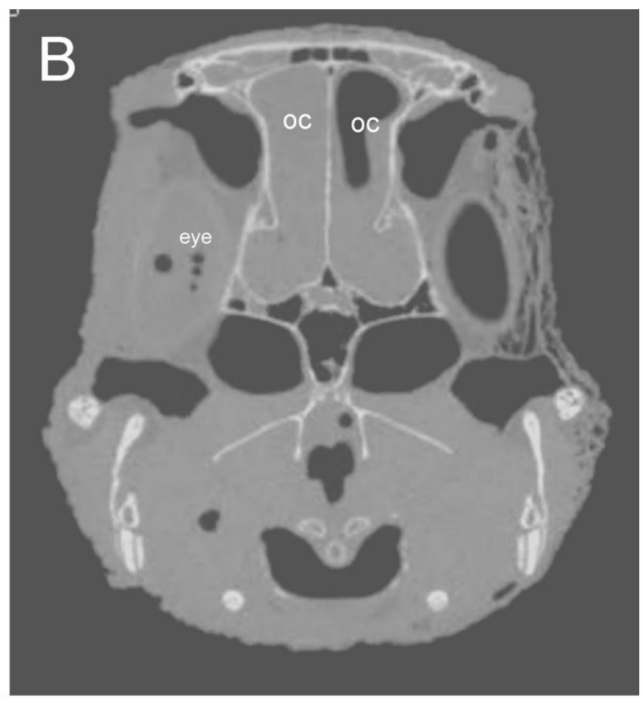

Coragyps atratus (Black Vulture)

Figure 11. Axial CT sections of olfactory chambers of vultures. (A), Cathartes aura, Turkey Vulture, (B), Coragyps atratus, Black Vulture. oc, olfactory chamber; s, sinus.

\section{Discussion}

We have presented a range of new information on the sensory systems of flightless birds from four different clades, variously linked by geography (NZ), nocturnality (kiwi, Kakapo), large size (moa, aepyornithids), and by the availability of data for our analyses.

We will summarise this new information for each group.

\subsection{Olfaction and Sensory Systems in Kiwi}

\subsubsection{Retronasal Olfaction}

The phenomenon of retronasal olfaction - entry of air to the olfactory epithelium via the internal nares-has been studied extensively in mammals, and indeed it has been asserted that retronasal olfaction is a unique attribute of mammals [54], and a separate neural pathway within the brain has been proposed. A little reflection, however, will show that retronasal olfaction must be possible in birds: a variety of aquatic birds, notably 
gannets and most penguins, do not have patent external nares (Figure 12) but do clearly have olfactory epithelium [13], so the retronasal route is the only possibility.

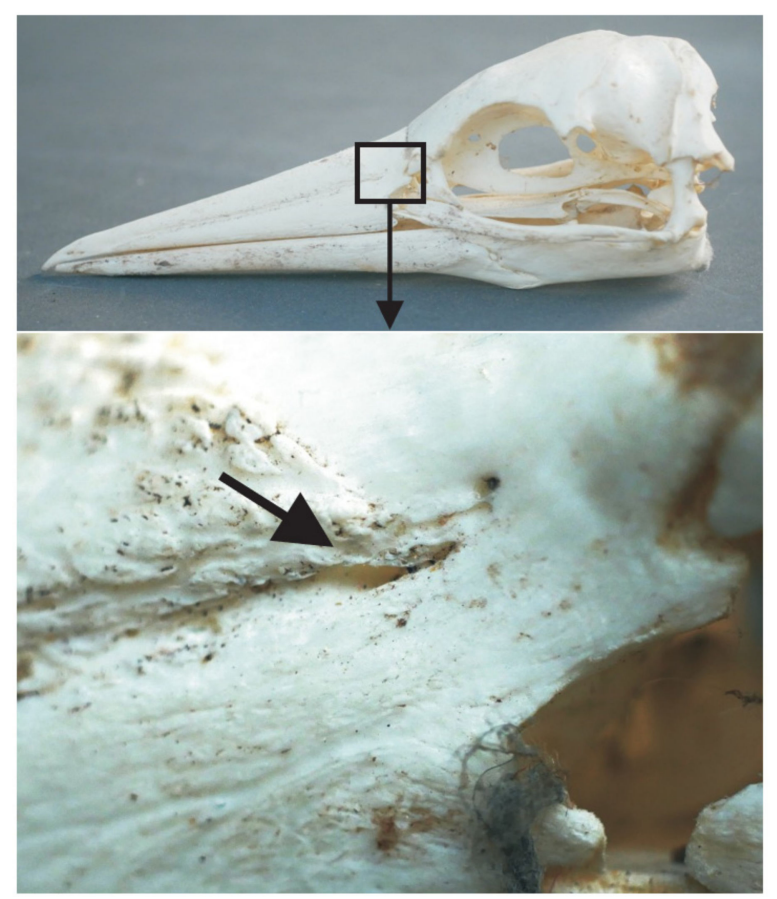

Figure 12. Australasian gannet, Morus serrator. skull with site of closed external naris indicated.

The Haagen-Poiseuille equation describes parameters for flow in pipes and other enclosed spaces:

$$
\Delta \mathrm{p}=8 \mu \mathrm{LQ} /\left(\pi \mathrm{R}^{\wedge} 4\right)=8 \pi \mu \mathrm{LQ} / \mathrm{A}^{2}
$$

where $\Delta \mathrm{p}=$ pressure difference, $\mu=$ viscosity, $\mathrm{L}=$ length, $\mathrm{Q}=$ flow rate, $\mathrm{A}=$ area.

When the function for area of pipes is considered, it is clear that resistance to flow is inversely proportional to the square of the area. When the data for the external and internal nares of Apteryx are used, the resistance of the external nares is 1200 times that of the internal nares. This, the proximity of the choana to the olfactory epithelium (Figure 4), and the baffle-like complex structure of the caudal concha, which presumably directs the air flow, make retronasal olfaction a likely or probably predominant mode of olfaction in kiwi.

Retronasal airflow has been assessed in a CFD study of pachycephalosaur dinosaurs [55], and the result does not appear to differ significantly from orthonasal flow.

The CFD analysis included here is a simplified simulation of a morphologically very complex airspace, but does support the hypothesis that retronasal air flow is the major mode of ventilation of the kiwi olfactory epithelium. In a more detailed analysis of flow in the intricate rat nasal airways [56], low velocity flow is seen in the olfactory area- this may be an advantage, in allowing longer odorant contact with the epithelium. A significant unknown factor is the speed of diffusion of odorants from the airstream to the olfactory receptors [56]. CFD could be applied widely in the investigation of avian olfaction; studies to date have relied on hypothetical flow distributions. A more advanced simulation with more detailed geometry and phasic inspiration-expiration flow could have offered more data for Apteryx.

\subsubsection{Sniffing}

It is not clear that sniffing, at least in the mammalian sense of short, noisy inspiratory air movement, or rapid cyclical inspiration and expiration, is actually possible in birds. The avian respiratory system operates at low pressures [29], and the extensive air sac network acts as capacitance mechanism that mitigates against any large or sudden pressure 
alteration on inspiration and expiration. Kiwi have typical large abdominal air sacs, and a non-muscular diaphragm [57]. The mammalian lung is tightly mechanically constrained within the thorax and capable of much greater pressure differences- negative pressures operating for sniffing in humans and rats is typically up to 10 times what avians are capable of [56]. The exit of secretions from nasal glands in birds has been described by [58]: nasal gland secretions are typically cleared via the external nares, and this activity, with expiratory effort, may account for the respiratory noises of kiwi. Mucus secretion from the respiratory epithelium is moved across the mucosal surfaces and leaves the nasal cavity via the internal nares. The bill elevation observed during kiwi olfactory search could be a mechanism for gravitationally directing secretions away from the small external nares. The small nares may be as much an issue for egress of nasal gland and lacrimal duct secretions as for air entry.

\subsection{Olfaction in Moa}

The data presented here support the hypothesis that moa were olfactory specialists, in spite of the minimally developed olfactory bulb (Figure 10C,D). The branching pattern of olfactory nerves at the cribriform plate and radiation of branches around the wall of the chamber are indicative of their supply to a broad area of olfactory epithelium; the nerve branches in the chamber in Rhea as demonstrated by [59], and in Procellariiformes as detailed by [58], are evidence for this. Furthermore, an olfactory chamber expanding the whole or much of the interorbital septum as in moa species is only otherwise found in neognath olfactory specialists such as vultures and Procellariiformes.

The evolutionary history of the avian interorbital septum can be deduced from accounts of developmental anatomy $[60,61]$. The region between the eyes is originally a tri-laminar structure: the midline septal cartilage is accompanied by an anterior orbital cartilage from each side. In most avians the latter structure disappears with the enlargement of the eye; in those cases where the tri-laminar configuration persists, an olfactory chamber and sinus cavities occupy the space between, and the midline septum may regress. In the early embryo, the olfactory capsules are directly applied to the forebrain; as the facial skeleton grows, the brain stem and olfactory capsules separate. The olfactory bulbs remain in contact with the capsules in fishes, and are connected with the rest of the brain by a peduncle. In amniotes, pedunculated bulbs remain in lepidosaur and archosaur lineages. In the theropod line towards avians, a progressive caudal retreat of an olfactory chamber and bulb toward the rest of the forebrain occur, to reach the situation found in birds where the bulb is sessile rather than pedunculated. A small peduncle may secondarily arise in birds with a large olfactory bulb (Figure 12E). With the enlarging avian eye, the olfactory chamber and bulb may become separated and a large olfactory nerve trunk traversing the orbit or interorbital septum results. There are thus two main patterns found in modern birds: a caudally extended olfactory chamber in apposition to the bulb, as in palaeognaths with the exception of tinamous and Rhea, which has a $1 \mathrm{~cm}$ single olfactory nerve; or alternatively a separation of bulb and chamber, which is found in most neognaths, with the exception of the olfactory specialists described above. Curiously, in amphibians and turtles, the bulb is contiguous with the telencephalon and a long single olfactory nerve trunk is present [62].

The ethmoid region in birds is made more complex by the variety of terminology that has been used, but an account of this region developed in an attempt to explain the same area in theropod dinosaurs [63] offers a clear explanation of the box-like separate ethmoid ossification seen in juvenile moa. The midline nasal septum is retained, the trough-like floor and sides of the cavity are formed from the anterior orbital cartilages (planum supraseptale), and its roof is the parieto-tectal cartilage [64], ossified as the 'dorsal plate'. This ethmoid structure is found in both neognaths and palaeognaths, where in the latter it may appear on the dorsum of the skull in juveniles, before being covered by the nasal bones. 
The evidence that moa are in fact olfactory specialists does contradict the inference from the evident olfactory bulb dimensions. The suggestion that components of the olfactory bulb may be buried in the bulk of the telencephalon [23] remains an open question. The forebrain of moa is shaped differently to other palaeognaths, as noted by its earliest observers $[16,65]$ : wider and blunter at its rostral end. Olfactory bulb size relative to brain size has been shown to follow allometric and phylogenetic trends [20] and empirical evidence of olfactory behaviour is available for only a limited range of birds; available evidence is sometimes not congruent with inference from brain morphology. We quote Graham Martin from his recent book on the sensory ecology of birds: 'how much of the brain is devoted to analysis of olfactory information does not seem to be a good guide to the importance of olfaction in the behaviour of birds' [1]. Much information on the exclusively herbivorous diet of moa has been gathered from preserved gizzard contents and coprolites, using direct examination for seeds and plant remains, and ancient DNA techniques [66], and a profile of the diet ranges for species of six moa genera has been assembled. Where data are sufficient, different diet preferences for sympatric moa species can be defined, indicating dietary selection. This research has also defined a range of plants present in their respective environments that were avoided by moa; both these positive and negative selection processes were presumably driven by olfaction. Moa had the genetic information for ultraviolet (UV) vision [67]; foliage that moa were known to eat has not been tested for its appearance in UV light but this could yield interesting results.

\subsection{Hearing in Moa}

We show that, with the parameters used here, Megalapteryx had more sensitive hearing than any other palaeognath. Without the need for hearing to hunt for prey, and in a relative absence of predators, hearing capacity may have been mainly needed for intraspecific communication. Rhea and Nothoprocta were included here to achieve a more complete palaeognath phylogeny; Rhea also has a more extensive hearing range than other palaeognaths with the exception of Megalapteryx; this is interesting, as Rhea is the only palaeognath with a complex syrinx [68], and they have a specific vocal profile [69]. The question of the syrinx in moa has been a little mysterious. Oliver [70] produced a figure evidently redrawn from Richard Owen [71], which was stated to be the tympanum of the syrinx of Emeus crassus. This attribution has not stood up to scrutiny $[15,68]$ and we agree with that position. However, we offer an alternative explanation. In Owen's original paper (p389) he described working out of matrix an expanded distal tracheal ring attached to an incomplete bronchial ring. His figure of this conforms with the description of a bifurcating lumen with a pessulus that he described as similar to that of a raven. Review of the original description of his raven [72] and its figure does indeed demonstrate a tympanum in the raven with a ventral fused band connecting four rings with a pessulus, similar to his Emeus account. This is quite convincing, but if so it is unusual that no other ossification compatible with a moa syrinx has been discovered [68]. We believe Oliver [70] was looking at the wrong drawing in Owen's figures and reworked a thyroid cartilage into the form of a very flattened and quite atypical syrinx. It is tempting to link a possible developed syrinx in Emeus with the sensitive hearing of Megalapteryx and the parallel with vocalisations as in Rhea as adaptations to intraspecific communication. However, interpretations from syringeal morphology must be guarded - 'vocal learners' among birds have the standard developed form of avian syrinx, as in the raven, whereas less vocally specialised birds can have a more elaborate syrinx [73], the adaptation in vocal learners being in more advanced neuromuscular control. Confirmation of a developed syrinx in moa together with that of Rhea would probably relegate the 'undeveloped' syrinx of other palaeognaths to a derived state, given the specific similarities between the syringes of Rhea and the typical tracheobronchial variety of neognath syrinx. 


\subsection{Vision in Moa}

Nocturnality and limited visual capacity in moa have been suggested or implied by observation of small optic lobes of the brain in recent studies [3,4]. A species for which scleral rings are known, $M$. didinus, is investigated here and found to fit within the published range of cathemeral birds. $M$. didinus had small optic lobes of the brain, similar to all other moa $[3,4,18]$. Other moa species may of course have been nocturnal, perhaps as a mode of niche partitioning in habitats where several moa species were sympatric. Cathemeral activity does, however, fit best with the pattern of other megaherbivores, which need to eat for a large part of the day to meet energy requirements [74].

The visual field map presented here for moa is differs from that of ostriches [75], in which the bill tip is not included in the visual field. The wide blind sector posteriorly could have presented an avenue of approach for the giant eagle Hieraaetus (Harpagornis) moorei: claw marks described on moa skeletal remains are on the dorsal trunk area [15]. There has been lengthy discussion on the flying abilities of this extinct eagle, given its weight (15 kg) and relatively short wings [15]. The ability of this extinct eagle to prey on moa many times its size and location of attack could suggest that gliding, silent flight on approach to the prey may have been the scenario, as flapping flight for a bird of this size would presumably have been quite noisy, and we have shown that at least one species of moa had sensitive hearing. The significance of a binocular field in birds has been explained as different from that in mammals: the binocular field is not for stereoscopic vision, and only represents a continuity of visual field [76]. Inclusion of the bill tip in the field is associated with foraging and the feeding of chicks. Moa chicks were presumably precocial, as with other ratites with large eggs, and may not have required direct parental feeding. In another study, visibility of the bill tip was related to a pecking foraging strategy; however, in birds relying on tactile foraging, the bill may or may not be included in the visual field [77].

\subsection{Bill-Tip Sensory Organ}

The presence of bill pits has not been studied formally in moa, although Richard Owen did notice these pits without being aware of their significance [16]. Their presence in moa is consistent with other palaeognaths. Their presence adds to the sensory repertoire used by moa to negotiate their environment; for example, a combination of olfaction and bill sensation would allow foraging among foliage in a context of low light or reduced visual acuity. The bill tip organ is also present in Kakapo [78], as in some other parrots. There are appear to be no comparative data on trigeminal ganglion endocast size, but the prominent structure in $M$. didinus is consistent with bill sensation as a major component of the sensory toolkit [79].

\subsection{Floccular Fossa Endocast}

The floccular lobe of the cerebellum is part of the central nervous system rather than a sensory organ, but is known to integrate visual and vestibular information and maintenance of a stable gaze [52,80] and thus relevant to those senses. Inferences from its morphology and size have not so far reached definite conclusions, and the significance of floccular fossa morphology remains enigmatic in any predictions regarding extinct taxa. We show here that $M$. didinus has a substantial floccular fossa endocast. This is in contrast to an observation that $D$. robustus had an absent flocculus [81]. The floccular endocast shows a range of morphologies within this single avian radiation [82], and future research in a phylogenetic context may bring another angle to bear on this question, particularly when combined with information about sensory systems and lifestyle.

\subsection{Kakapo}

The Kakapo S. habroptilus also has a herbivorous diet and nocturnal lifestyle, and has specific visual specializations for nocturnality, in that the retina is adapted for light sensitivity and not for visual acuity [9]. Strigops is known to use olfactory cues in feeding [83] and has a larger repertoire of olfactory receptor genes [84], but with a relative olfactory 
bulb size in phylogenetic context which in the middle of the avian range when corrected for allometry and phylogeny [20]. We see here and in [36] that the hearing range of this bird is at the lower end of the range, similar to the findings in kiwi and elephant birds. Our new data on the Kakapo scleral ring modifies the analysis of eye dimensions alone [9], which had described the optics of the eye as resembling those of diurnal birds. This helps to validate our predictive framework for moa and other birds in the data set.

\subsection{Aepyornithids}

Previous research has shown an olfactory bulb of comparable proportions to other palaeognaths [4], and small eyes are a feature of the skull. We add here the information that a moderately large olfactory chamber was present, and that the hearing range was limited, among the lowest in the birds studied here and by [36]. The optic lobes of the brain were very small [4], of an equivalent size to those of kiwi, suggesting a nocturnal activity pattern. Very little is known of elephant bird ecology [14]; it could be expected that olfaction comprised a major part of the sensory repertoire.

\section{Conclusions}

We return to the concept of complementary sensory information in birds and trade-offs among different senses. This expectation has been demonstrated more readily in mammals than in birds, where the best documented example is the reduction of other senses in instances of dominant bill sensation- trigeminal hypertrophy taxa [85]. Following [36], we have plotted nocturnality against ECD length from our data where both are available (Figure 13)-(the 'posterior probability of nocturnality' is only relevant to $M$. didinus here) - and a tendency for increased hearing sensitivity is observed in nocturnal birds, Apteryx being a notable exception. This plot also indicates Megalapteryx ranked for ECD among our dataset. If we follow some of the published suggestions, we could conclude that moa had both diminished visual and olfactory ability. How, then would moa thrive in their herbivorous mode of life in a variety of habitats? The balance is obvious in extreme sensory specialisations, such as olfaction in kiwi and hearing in some owls; in most cases, multiple sources of information must be viewed together. Palaeoneurology explores the limits of inference; in this context, some morphometric studies of brain shape in birds and mammals conclude that brain shape is responsive to dimensions of the eyes and facial skeleton $[86,87]$, and a recent theme in cranial morphometrics is that the various facial, muscular, sensory and central neural structures compete for space within the head, and that this may explain the shapes of structures as much as individual functional needs $[88,89]$. Thus, as well as sensory complementarity and trade-offs, and the metabolic cost of supporting sensory structures and brain regions to support them [85], we also have to consider competition for the cranial domain. From the data we have assembled here and reviewed in the literature, we can offer tentative hypotheses regarding these tradeoffs in our taxa (Figure 14). These are necessarily global assessments from the multiple sources of evidence we have discussed; different patterns of sensory use would presumably apply for feeding, reproductive, intraspecific and interspecific requirements. We have not examined vestibular anatomy as a recent comprehensive study could not reveal any significant functional inferences from this domain [89].

Here, we need to ask what part flightlessness plays in the sensory patterns of the taxa considered here. There is an association between reduction of flight muscles and increase in brain size [90]; this applies to kiwi but not to the other taxa we have addressed: moa have small brains [18] and Kakapo brains are not larger than those of other parrots [9]. Aepyornithids appear to have small brains but the rarity of associated cranial and postcranial remains makes measurement of brain/body mass uncertain. Kiwi have obvious hypertrophy of the olfactory lobe of the brain, but otherwise, 'whole brain size is a blunt instrument when it comes to assessing avian brain evolution' [2].

In an analysis of potential factors enabling flightlessness in many lineages of islanddwelling birds, absence of predation stood out in the evolution of reduced flight muscles 
and longer hind limbs [91]. How might this have affected sensory evolution in the island taxa we have considered? A reduction in the need for auditory and visual monitoring for predators may have enabled reductions in those systems and made these birds highly vulnerable to introduced predators: the extinction of moa and aeypornithids was related to human arrival on their respective islands [15,92], Kakapo are currently critically endangered, and kiwi are protected as they are vulnerable to introduced mustelids, rodents, and domestic animals.

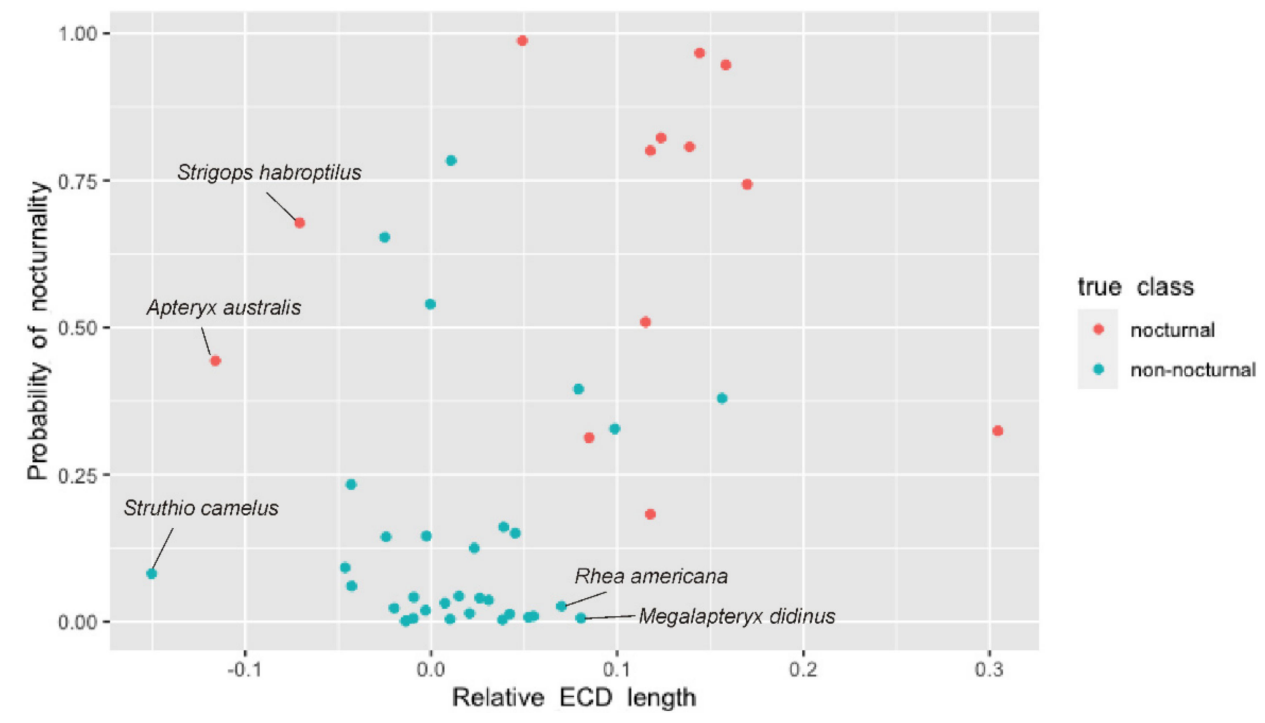

Figure 13. Plot of endosseous cochlear duct residuals against probability of nocturnality from eye measurements.

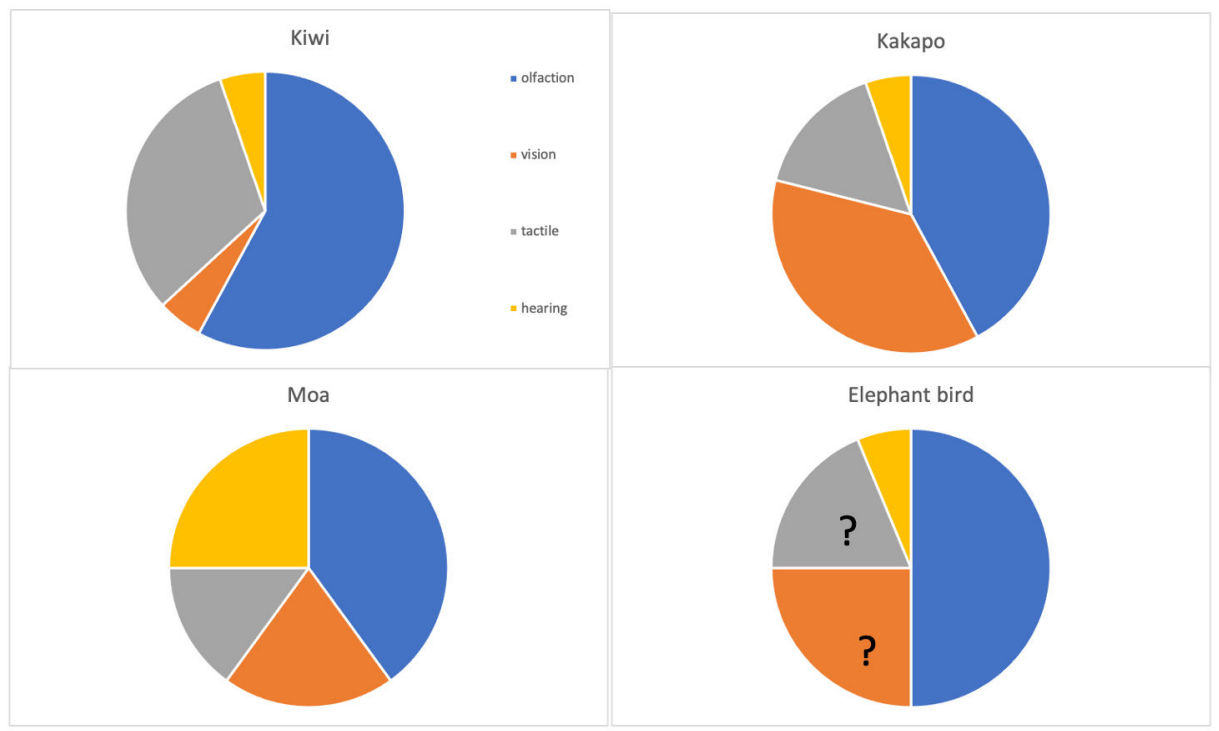

Figure 14. Possible patterns of sensory modalities, based on new date and published information on sensory organs, neural structures and observed behavior. ? = unknown.

Trade-offs among sensory systems are apparent in the extant taxa we have studied, but remain conflicting and incomplete for the extinct birds. To take these questions further, our ongoing research includes geometric morphometrics of endocasts and other domains of cranial morphology, and interrogation of ancient DNA data in all moa genera for signals of positive selection of in genes known to be associated with sensory modalities and nocturnality. The data we have presented here form a baseline for these and other investigations. 
Supplementary Materials: The following are available online at https:/ /www.mdpi.com/article/10 .3390/d13110538/s1, Table S1 eye data (.csv); Table S2: ECD data (.csv); Table S3: sequence data.

Author Contributions: Concept: P.J., K.J.M.; methodology: P.J., K.J.M.; morphological analyses, P.J.; constructed phylogenetic trees, K.J.M.; original draft preparation, P.J.; reviewing and editing, P.J., K.J.M. All authors have read and agreed to the published version of the manuscript.

Funding: K.J.M. is supported by a Marsden Fund Fast-Start Grant (20-UOO-130).

Institutional Review Board Statement: No animal interventions were used in this research.

Data Availability Statement: microCT series of M. didinus and Amira Mesh segmentation file are available on request.

Acknowledgments: For access to collections (for abbreviations see Appendix A) we thank; AIM, Brian Gill, Jason Froggatt; MNZ, Alan Tennyson; MNHN, Ronan Allain and Romain David; Tübingen Zoologische Sammlung, Wolfgang Maier and Erich Weber. We are also grateful to Lars Schmitz for permission to reproduce Figure 7B, Graham Martin for his visual field grid, and for information and discussion, Trevor Worthy, Brian Gill and Martin Wild. Hamish Johnston kindly assisted with data analysis. Contributors to online resources are acknowledged with individual specimens in Appendix A.

Conflicts of Interest: The authors declare no conflict of interest.

Abbreviations: AIM: Auckland Museum; MNZ: Museum of New Zealand, Te Papa Tongarewa; JVC: author's collection (PJ); ZSUT: Zoologische Sammlung Universität Tübingen; AMNH, American Museum of Natural History; SAM, South Australia Museum; TMM, Texas Memorial Museum; UMHN, Utah Museum of Natural History.

\section{Appendix A}

Material Examined

Named contributors to online resources and individual requests are gratefully acknowledged.

- Moa:

- Dinornis novaezealandiae: MNZ S37876; AIM: LB6400; LB6952; LB7870; LB6952; LB6400; LB6833; LB6401; LB6310; LB 6308; LB6432;

- Dinornis robustus: MNZ S28225

- Anomalopteryx didiformis MNZ S35274; MNZ S5795; AIM: LB5548; LB5545; LB5979; LB5596; LB5819; LB5796; LB5843; LB5465; LB5485; LB5504; LB5515; LB5519; LB5511; LB5552; LB5553; LB5555; LB5550; LB5593; LB5596; lb5627; LB5793; LB5620; LB5653; LB5684; LB5914; LB5798; LB5819;

- Emeus crassus MNZ S470; MNZ S792; AIM: LB6285;

- Euryapteryx curtus MNZ S30212; AIM LB6710; LB6637; LB6616; LB6666; LB6246; LB6251; LB6285;

- $\quad$ Pachyornis elephantopus AIM: LB5946

- Pachyornis geranoides AIM: LB6030; LB6020; LB6021; LB6024; LM6069;

- $\quad$ Pachyornis australis MNZ S27896

- $\quad$ Megalapteryx didinus MNZ S28206; MNZ S33763; MNZ S400; AIM: LB5904;

- Moa: CT scans: D. robustus MNZ S28225, A. didiformis MNZ S35274, E. crassus, MNZ S470, E. curtus, MNZ S30212, P. australis MNZ S27896, M.didinus, MNZ S28206. Pacific Radiology, Wellington (New Zealand), on a General Electric Discovery CT750 HD scanner, at $80 \mathrm{kV}$ and $40 \mu \mathrm{A}$, and reconstructed as axial $0.3 \mathrm{~mm}$ slices).

- P. elephantopus AIM LB5946; Mercy Radiology, Auckland. GE Discovery CT750, 120 kV, $150 \mathrm{~mA}, 0.625 \mathrm{~mm}$ slices.

- P. elephantopus MNHN 1875-602, from Dryad Digital Repository https:/ / doi.org/10.5 061/dryad.7519042 (accessed on 14 September 2021), C. Torres and J. Clarke 
- $\quad$ M. didinus AIM LB5904, microCT scan (30.5.2011,Bioengineering Institute, University of Auckland; Skyscan 1172: $100 \mathrm{kV}, 100 \mu \mathrm{A}$, reconstructed as 1626 slices, voxel size $34.6 \mu \mathrm{m}$, image size $1984 \times 1984$ pixels).

- Moa: MRI scan: M. didinus, MNZ S400 Siemens Magnetom Avanto 1.5 Tesla scanner with a Siemens 12 channel head matrix coil and B17 software. Performance per axis details were: maximum amplitude $33 \mathrm{mT} / \mathrm{m}$, minimum rise time 264 microseconds from $0-33 \mathrm{mT} / \mathrm{m}$, maximum slew rate $125 \mathrm{~T} / \mathrm{m} / \mathrm{s}$.

- Kiwi:

- Apteryx mantelli: JVC 386, JVC 387; AIM LB7709; LB7289; LB2182; LB5540; LB7202; LB5539; LB9246; LB14145;

- Apteryx australis: AIM LB13427; LB2182

- Apteryx owenii: AIM LB9427; LB11246

- Kiwi: CT scan: Apteryx species-AMHN18456, http://digimorph.org/specimens/ Apteryx_sp / (accessed on 14 September 2021).

- Kiwi: MRI scan: Apteryx mantelli: Centre for Advanced MRI, University of Auckland. Siemens Magnetom Avanto 1-5T, gradient strength 40 (across) and 45 (along) mTm-1, maximum slew rate $200 \mathrm{Tm}-1 \mathrm{~s}-1$ with a 4-channel wrist coil; 2D turbo spin echo with $0.4 \mathrm{~mm}$ in-plane resolution and $1 \mathrm{~mm}$ slice thickness; echo time/repetition time/flip angle/averages $=156 \mathrm{~ms} / 5510 \mathrm{~ms} / 1501 / 6$-Jeremy Corfield

- Kiwi, histological series: ZSUT-SAJ78110. Apteryx australis. Serial sectioned head of hatchling

- Aepyornithidae:

- Aepyornis maximus MNHN 1910.12; Ae. ?hildebrandti MNHN MAD6724; Ae. 'medius' MNHN1911-27

- $\quad$ microCT scan: Ae. maximus MNHN 1910.12; 629 slices at voxel size $138 \mu$ m; Romain Allain and Ronan David

- Struthio camelus: JVC 343; AIM LB11730

- CT scan: L. Witmer lab: https://people.ohio.edu/witmerl/3D_ostrich.htm; https: / / youtu.be/gDQ8a0_oH6k (accessed on 14 September 2021).

- $\quad$ Dromaeus novaehollandiae: JVC355; AIM541

- CT scan, SAM39373,-Trevor Worthy

- Rhea americana TMM M-6721, from Dryad Digital Repository https://doi.org/10.506 1/dryad.7519042 (accessed on 14 September 2021), C. Torres and J. Clarke

- Casuarius casuarius TMM M-12033, from Dryad Digital Repository https://doi.org/10 .5061 /dryad.7519042 (accessed on 14 September 2021), C. Torres and J. Clarke

- Rhea pennata: AIM LB1216

- Nothoprocta pericardia, UMNH 23838, from Dryad Digital Repository https:/ / doi.org/ 10.5061/dryad.7519042, C. Torres and J. Clarke

- Morus serrator (Australasian gannet): JVC201

- Cathartes aura (Turkey Vulture); Morphosource 000125045, Jessie Maisano

- Coragyps atratus (Black Vulture); http://digimorph.org/specimens/Coragyps_atratus/ (accessed on 14 September 2021)-Tim Rowe

- Stripogs habroptilus (Kakapo): Morphosource 000158358, Roger Benson

- Pachyptila desolata: Morphosource 000167145, Jeff Zeyl

- Thalassarche chlororhynchos: Morphosource 000166936, Jeff Zeyl

- Fulmaris glacialis: Morphosource 000032762 Roger Benson

- Puffinus grisea: Morphosource 000166694, Jeff Zeyl

- Phoebastria immutabilis: http://digimorph.org/specimens/Diomedea_immutabilis/ (accessed on 14 September 2021)-Tim Rowe.

\section{References}

1. Martin, G.R. The Sensory Ecology of Birds, 1st ed.; Oxford University Press: Oxford, UK, 2017; p. 296.

2. Knoll, F.; Kawabe, S. Avian palaeoneurology: Reflections on the eve of its 200th anniversary. J. Anat. 2020, 236, 965-979. [CrossRef] 
3. Early, C.M.; Ridgely, R.C.; Witmer, L.M. Beyond Endocasts: Using Predicted Brain-Structure Volumes of Extinct Birds to As-sess Neuroanatomical and Behavioral Inferences. Diversity 2020, 12, 34. [CrossRef]

4. Torres, C.R.; Clarke, J.A. Nocturnal giants: Evolution of the sensory ecology in elephant birds and other palaeognaths inferred from digital brain reconstructions. Proc. R. Soc. B 2018, 285, 20181540. [CrossRef] [PubMed]

5. Yonezawa, T.; Segawa, T.; Mori, H.; Campos, P.; Hongoh, Y.; Endo, H.; Akiyoshi, A.; Kohno, N.; Nishida, S.; Wu, J.; et al. Phylogenomics and Morphology of Extinct Paleognaths Reveal the Origin and Evolution of the Ratites. Curr. Biol. 2017, 27, 68-77. [CrossRef] [PubMed]

6. Grealy, A.; Phillips, M.; Miller, G.; Gilbert, M.; Rouillard, J.-M.; Lambert, D.; Bunce, M.; Haile, J. Eggshell palaeogenomics: Palaeognath evolutionary history revealed through ancient nuclear and mitochondrial DNA from Madagascan elephant bird (Aepyornis sp.) eggshell. Mol. Phylogenetics Evol. 2017, 109, 151-163. [CrossRef] [PubMed]

7. Phillips, M.J.; Gibb, G.C.; Crimp, E.A.; Penny, D. Tinamous and Moa Flock Together: Mitochondrial Genome Sequence Analysis Reveals Independent Losses of Flight among Ratites. Syst. Biol. 2009, 59, 90-107. [CrossRef] [PubMed]

8. Mitchell, K.J.; Llamas, B.; Soubrier, J.; Rawlence, N.J.; Worthy, T.H.; Wood, J.R.; Lee, M.S.Y.; Cooper, A. Ancient DNA reveals elephant birds and kiwi are sister taxa and clarifies ratite bird evolution. Science 2014, 344, 898-900. [CrossRef]

9. Corfield, J.R.; Gsell, A.C.; Brunton, D.; Heesy, C.P.; Hall, M.I.; Acosta, M.; Iwaniuk, A. Anatomical Specializations for Nocturnality in a Critically Endangered Parrot, the Kakapo (Strigops habroptilus). PLoS ONE 2011, 6, e22945. [CrossRef] [PubMed]

10. Castro, I.; Cunningham, S.J.; Gsell, A.C.; Jaffe, K.; Cabrera, A.; Liendo, C. Olfaction in birds: A closer look at the Kiwi (Apterygidae). J. Avian Biol. 2010, 41, 213-218. [CrossRef]

11. Owen, R. Memoirs on the Extinct Wingless Birds of New Zealand, with an Appendix on Those of England, Australia, New Foundland, Mauritius and Rodriquez; John van Voorst: London, UK, 1879.

12. Corfield, J.; Eisthen, H.L.; Iwaniuk, A.N.; Parsons, S. Anatomical specialisations for enhanced olfactory sensitivity Kiwi, Ap-teryx mantelli. Brain Behav. Evol. 2014, 84, 214-226. [CrossRef]

13. Bang, B. Functional Anatomy of the Olfactory System in 23 Orders of Birds. Acta Anat. 1971, 79 (Suppl. 1), 1-76. [CrossRef] [PubMed]

14. Hansford, J.P.; Turvey, S.T. Unexpected diversity within the extinct elephant birds (Aves: Aepyornithidae) and a new identity for the world's largest bird. R. Soc. Open Sci. 2018, 5, 181295. [CrossRef] [PubMed]

15. Worthy, T.H.; Holdaway, R.N. The Lost World of Moa; Indiana University Press: Bloomington, IN, USA, 2002.

16. Owen, R. On Dinornis (part XXIII): Containing a description of the head and feet, with their dried integuments, of an indi-vidual of the species Dinornis didinus, Owen. Trans. Zool. Soc. Lond. 1883, 11, 257-261.

17. Parker, T.J. On the cranial osteology, classification and phylogeny of Dinornithidae. Transactions of the Zoological Society of London. 1895, 8, 373-428. [CrossRef]

18. Ashwell, K.; Scofield, R. Big Birds and Their Brains: Paleoneurology of the New Zealand Moa. Brain Behav. Evol. 2007, 71, 151-166. [CrossRef] [PubMed]

19. Corfield, J.R.; Wild, J.; Hauber, M.E.; Parsons, S.; Kubke, M.F. Evolution of Brain Size in the Palaeognath Lineage, with an Emphasis on New Zealand Ratites. Brain Behav. Evol. 2007, 71, 87-99. [CrossRef]

20. Corfield, J.R.; Price, K.; Iwaniuk, A.N.; Gutiérrez-Ibáñez, C.; Birkhead, T.; Wylie, D.R. Diversity in olfactory bulb size in birds reflects allometry, ecology, and phylogeny. Front. Neuroanat. 2015, 9, 102. [CrossRef] [PubMed]

21. Zelenitsky, D.K.; Therrien, F.; Ridgely, R.C.; McGee, A.R.; Witmer, L. Evolution of olfaction in non-avian theropod dinosaurs and birds. Proc. R. Soc. B. 2011, 278, 3625-3634. [CrossRef]

22. Atkinson, I.A.E.; Greenwood, R.M. Relationships between moas and plants. N. Z. J. Ecol. 1989, 12, 67-96.

23. Worthy, T.H. Aspects of the biology of two moa species (Aves: Dinornithiformes). N. Z. J. Archaeol. 1989, 11, 77-86.

24. Vickers-Rich, P.; Trusler, P.; Rowley, M.J.; Cooper, A.; Chambers, G.K.; Bock, W.J.; Millener, P.; Worthy, T.H.; Yaldwyn, J.C. Morphology, Myology, Collagen and DNA of a Mummified Uplandmoa, Megalapteryx Didinus (Aves: Dinornithiformes) from New Zealand. Tuhinga Rec. Mus. New Zealand Te Papa Tongarewa 1995, 4, 1-26.

25. Rawlence, N.; Wood, J.; Scofield, R.; Fraser, C.; Tennyson, A.; Wood, J.; Scofield, R. Soft-tissue specimens from pre-European extinct birds of New Zealand. J. R. Soc. N. Z. 2013, 43, 154-181. [CrossRef]

26. Attard, M.R.G.; Wilson, L.A.B.; Worthy, T.H.; Scofield, R.P.; Johnston, P.; Parr, W.H.C.; Wroe, S.R. Moa diet fits the bill: Virtual reconstruction incorporating mummified remains and prediction of biomechanical performance in avian giants. Proc. R. Soc. $B$ 2016, 283, 20152043. [CrossRef]

27. Simscale. Available online: https://www.simscale.com (accessed on 14 September 2021).

28. Autodesk Meshmixer. Available online: https://www.meshmixer.com (accessed on 14 September 2021).

29. Brackenbury, J.H. Lung-Air-Sac Anatomy and Respiratory Pressures in the Bird. J. Exp. Biol. 1972, 57, 543-550. [CrossRef] [PubMed]

30. Beale, G. A radiological study of the kiwi (Apteryx australis mantelli). J. R. Soc. N. Z. 1985, 15, 187-200. [CrossRef]

31. Morphosource. Available online: https:/ / www.morphosource.org (accessed on 14 September 2021).

32. Rowe, T.B. Digimorph. Available online: http://digimorph.org/index.phtml (accessed on 14 September 2021).

33. Goswami, A. Phenome10K: A Free Online Repository for 3-D Scans of Biological and Palaeontological Specimens. Available online: www.phenome10k.org. (accessed on 14 September 2021).

34. Witmer, L.M. WitmerLab. Available online: https:/ / people.ohio.edu/witmerl/projects.htm (accessed on 14 September 2021). 
35. Community, B.O. Blender-A 3D Modelling and Rendering Package. Available online: http:/ /www.blender.org. (accessed on 14 September 2021).

36. Choiniere, J.N.; Neenan, J.M.; Schmitz, L.; Ford, D.P.; Chapelle, K.E.J.; Balanoff, A.M.; Sipla, J.S.; Georgi, J.A.; Walsh, S.A.; Norell, M.A.; et al. Evolution of vision and hearing modalities in theropod dinosaurs. Science 2021, 372, 610-613. [CrossRef]

37. Schmitz, L.; Motani, R. Morphological differences between the eyeballs of nocturnal and diurnal amniotes revisited from op-tical perspectives of visual environments. Vis. Res. 2010, 50, 936-946. [CrossRef]

38. Pinheiro, J.; Bates, D.; DebRoy, S.; Sarkar, D.; Team, R.C. Nlme: Linear and Nonlinear Mixed Effects Models. 2014. Available online: http:/ /CRAN.R-project.org/package=nlme (accessed on 30 October 2020).

39. Paradis, E.; Schliep, K. ape 5.0: An environment for modern phylogenetics and evolutionary analyses in R. Bioinform. 2018, 35, 526-528. [CrossRef] [PubMed]

40. Walsh, S.A.; Barrett, P.M.; Milner, A.C.; Manley, G.; Witmer, L.M. Inner ear anatomy is a proxy for deducing auditory capa-bility and behaviour in reptiles and birds. Proc. R. Soc. B 2009, 276, 1355-1360. [CrossRef] [PubMed]

41. Hackett, S.J.; Kimball, R.T.; Reddy, S.; Bowie, R.C.K.; Braun, E.L.; Braun, M.J.; Chojnowski, J.L.; Cox, W.A.; Han, K.-L.; Harshman, J.; et al. A Phylogenomic Study of Birds Reveals Their Evolutionary History. Science 2008, 320, 1763-1768. [CrossRef]

42. Jetz, W.; Thomas, G.; Joy, J.B.; Hartmann, K.; Mooers, A.O. The global diversity of birds in space and time. Nat. Cell Biol. 2012, 491, 444-448. [CrossRef] [PubMed]

43. Edgar, R.C. MUSCLE: Multiple sequence alignment with high accuracy and high throughput. Nucleic Acids Res. 2004, 32, 1792-1797. [CrossRef]

44. Geneious Prime. Available online: http://www.geneious.com/ (accessed on 7 April 2020).

45. Drummond, A.J.; Rambaut, A. BEAST: Bayesian evolutionary analysis by sampling trees. BMC Evol. Biol. 2007, 7, 214. [CrossRef] [PubMed]

46. Nguyen, L.-T.; Schmidt, H.A.; Von Haeseler, A.; Minh, B.Q. IQ-TREE: A Fast and Effective Stochastic Algorithm for Estimating Maximum-Likelihood Phylogenies. Mol. Biol. Evol. 2015, 32, 268-274. [CrossRef]

47. Kalyaanamoorthy, S.; Minh, B.Q.; Wong, T.K.F.; Von Haeseler, A.; Jermiin, L.S. ModelFinder: Fast model selection for accurate phylogenetic estimates. Nat. Methods 2017, 14, 587-589. [CrossRef]

48. Jarvis, E.D.; Mirarab, S.; Aberer, A.J.; Li, B.; Houde, P.; Li, C.; Ho, S.Y.W.; Faircloth, B.C.; Nabholz, B.; Howard, J.T.; et al. Whole-genome analyses resolve early branches in the tree of life of modern birds. Science 2014, 346, 1320-1331. [CrossRef]

49. Cloutier, A.; Sackton, T.B.; Grayson, P.; Clamp, M.; Baker, A.J.; Edwards, S.V. Whole-Genome Analyses Resolve the Phylogeny of Flightless Birds (Palaeognathae) in the Presence of an Empirical Anomaly Zone. Syst. Biol. 2019, 68, 937-955. [CrossRef]

50. Rambaut, A.; Drummond, A.J.; Xie, D.; Baele, G.; Suchard, M.A. Posterior Summarization in Bayesian Phylogenetics Using Tracer 1.7. Syst. Biol. 2018, 67, 901-904. [CrossRef] [PubMed]

51. Marples, B.J. The Structure and Development of the Nasal Glands of Birds. Proc. Zool. Soc. Lond. 1932, 102, 829-844. [CrossRef]

52. Walsh, S.A.; Iwaniuk, A.; Knoll, M.A.; Bourdon, E.; Barrett, P.M.; Milner, A.C.; Nudds, R.L.; Abel, R.L.; Sterpaio, P.D. Avian Cerebellar Floccular Fossa Size Is Not a Proxy for Flying Ability in Birds. PLoS ONE 2013, 8, e67176. [CrossRef]

53. Grigg, N.P.; Krilow, J.M.; Gutierrez-Ibanez, C.; Wylie, D.R.; Graves, G.R.; Iwaniuk, A.N. Anatomical evidence for scent guided foraging in the turkey vulture. Sci. Rep. 2017, 7, 17408. [CrossRef] [PubMed]

54. Rowe, T.B.; Shepherd, G.M. Role of ortho-retronasal olfaction in mammalian cortical evolution. J. Comp. Neurol. 2016, 524, 471-495. [CrossRef] [PubMed]

55. Bourke, J.M.; Porter, W.R.; Ridgely, R.C.; Lyson, T.R.; Schnachner, E.R.; Bell, P.R.; Witmer, L.M. Breathing life into dinosaurs: Tackling challenges of soft-tissue restoration and nasal airflowiin extinct species. Anat. Rec. 2014, 297, 2148-2186. [CrossRef] [PubMed]

56. Zhao, K.; Dalton, P.; Yang, G.C.; Scherer, P.W. Numerical Modeling of Turbulent and Laminar Airflow and Odorant Transport during Sniffing in the Human and Rat Nose. Chem. Senses 2006, 31, 107-118. [CrossRef] [PubMed]

57. Huxley, T.H. On the Respiratory Organs of Apteryx. Proc. Zool. Soc. Lond. 1882, 50, 560-569. [CrossRef]

58. Bang, B.G.; Wenzel, B.M. Nasal cavity and olfactory system. In Form and Function in Birds; King, A.S., McLelland, J., Eds.; Academic Press: London, UK, 1985; Volume 3, pp. 195-225.

59. Müller, H. Die Morphologie und Entwicklung des Craniums von Rhea americana Linné. Z. Für Wissensschaftliche Zoologie 1961, 165, 221-319.

60. Bellairs, A.D. The Early Development of the Interorbital Septum and the Fate of the Anterior Orbital Cartilages in Birds. J. Embryol. Exp. Morphol. 1958, 6, 68-85. [CrossRef]

61. Hüppi, E.; Werneburg, I.; Sánchez-Villagra, M.R. Evolution and development of the bird chondrocranium. Front. Zool. 2021, 18, 21. [CrossRef]

62. Parsons, T.S. Nasal Anatomy and the Phylogeny of Reptiles. Evolution 1959, 13, 175-187. [CrossRef]

63. Ali, F.; Zelenitsky, D.K.; Therrien, F.; Weishampel, D.B. Homology of the "Ethmoid Complex" of Tyrannosaurids and its im-plications for reconstruction of the olfactory apparatus of non-avian theropods. J. Vertebr. Paleontol. 2008, $28,123-133$. [CrossRef]

64. Parker, T.J., II. Observation on the anatomy and development of apteryx. Philos. Trans. R. Soc. London. Ser. B Biol. Sci. 1891, 182, 25-134. [CrossRef] 
65. Starck, D. Die endokraniale Morphologie der Ratiten, besonders der Apterygidae und Dinornithidae. Morphol. Jahrb. 1955, 96, $14-72$.

66. Wood, J.; Richardson, S.; McGlone, M.; Wilmshurst, J. The diets of moa (Aves: Dinornithiformes). N. Z. J. Ecol. 2020, 44, 3397. [CrossRef]

67. Aidala, Z.; Huynen, L.; Brennan, P.L.R.; Musser, J.; Fidler, A.; Chong, N.; Capuska, G.E.M.; Andersen, M.G.; Tabala, A.; Lambert, D.; et al. Ultraviolet visual sensitivity in three avian lineages: Palaeognaths, parrots, and passerines. J. Comp. Physiol. A 2012, 198, 495-510. [CrossRef]

68. McInerney, P.L.; Lee, M.S.Y.; Clement, A.M.; Worthy, T.H. The phylogenetic significance of the morphology of the syrinx, hyoid and larynx, of the southern cassowary, Casuarius casuarius (Aves, Palaeognathae). BMC Evol. Biol. 2019, 19, 1-18. [CrossRef]

69. Pérez-Granados, C.; Schuchmann, K.-L. Vocalisations of the Greater Rhea (Rhea americana): An allegedly silent ratite. Bioacoustics 2021, 30, 564-574. [CrossRef]

70. Oliver, W.R.B. The Moas of New Zealand and Australia; Dominion Museum, Bulletin 15: Wellington, New Zealand, 1949.

71. Owen, R. On Dinornis (part XVI): Containing notices of the internal organs of some species, with a description of the brain and some nerves and muscles of the head of Apteryx australis. Trans. Zool. Soc. Lond. 1871, 7, 381-396. [CrossRef]

72. Owen, R. On the Anatomy of Vertebrates; Longmans, Green: London, UK, 1866; Volume 2.

73. Garcia, S.M.; Kopuchian, C.; Mindlin, G.B.; Fuxjager, M.J.; Tubaro, P.L.; Goller, F. Evolution of vocal diversity through morphological adaptation without vocal learning or complex neural control. Curr. Biol. 2017, 27, 2677-2683. [CrossRef]

74. Leader-Williams, N.; Owen-Smith, R.N. Megaherbivores: The Influence of Very Large Body Size on Ecology. J. Anim. Ecol. 1990, 59, 381. [CrossRef]

75. Martin, G.; Osorio, D.; Masland, D.; Albright, T.D. Vision in birds. In The Senses: A Comprehensive Reference; Masland, R.H., Al-bright, T.D., Dallos, P., Oertel, D., Firestein, S., Beauchamp, G.K., Bushnell, M.C., Basbaum, A., Kaas, J.H., Gardner, E.P., Eds.; Academic Press: Cambridge, MA, USA, 2008; Volume 1.

76. Martin, G.R. What is binocular vision for? A birds' eye view. J. Vis. 2009, 9, 14. [CrossRef]

77. Tyrrell, L.P.; Fernández-Juricic, E. Avian binocular vision: It's not just about what birds can see, it's also about what they can't. PLoS ONE 2017, 12, e0173235. [CrossRef]

78. Froggatt, J.; Gill, B. Bill morphology reflects adaptation to a fibrous diet in the kākāpō (Strigops: Psittaciformes). N. Z. J. Zool. 2016, 43, 138-148. [CrossRef]

79. Crole, M.R.; Soley, J. Comparative morphology, morphometry and distribution pattern of the trigeminal nerve branches supplying the bill tip in the ostrich (Struthio camelus) and emu (Dromaius novaehollandiae). Acta Zool. 2016, 97, 49-59. [CrossRef]

80. Ferreira-Cardoso, S.; Araújo, R.; Martins, N.; Martins, G.; Walsh, S.; Martins, R.M.S.; Kardjilov, N.; Manke, I.; Hilger, A.; Castanhinha, R. Floccular fossa size is not a reliable proxy of ecology and behaviour in vertebrates. Sci. Rep. 2017, 7, 2005. [CrossRef] [PubMed]

81. Early, C.M. Quantitative Assessments of Avian Endocasts as Tools for Inferring Neuroanatomical Traits and Potential Functional Capabilities; Ohio University: Athens, OH, USA, 2019.

82. Johnston, P. Unpublished obeservations: Endocast Diversity in Moa. 2021.

83. Hagelin, J.C. Observations on the olfactory ability of the Kakapo Strigops habroptilus, the critically endangered parrot of New Zealand. Ibis 2003, 146, 161-164. [CrossRef]

84. Steiger, S.S.; Fidler, A.E.; Kempenaers, B. Evidence for increased olfactory receptor gene repertoire size in two nocturnal bird species with well-developed olfactory ability. BMC Evol. Biol. 2009, 9, 117. [CrossRef] [PubMed]

85. Wylie, D.R.; Gutiérrez-Ibáñez, C.; Iwaniuk, A.N. Integrating brain, behavior, and phylogeny to understand the evolution of sensory systems in birds. Front. Neurosci. 2015, 9, 281. [CrossRef]

86. Selba, M.C.; Bryson, E.R.; Rosenberg, C.L.; Heng, H.G.; DeLeon, V.B. Selective breeding in domestic dogs: How selecting for a short face impacted canine neuroanatomy. Anat. Rec. Adv. Integr. Anat. Evol. Biol. 2021, 304, 101-115. [CrossRef]

87. Kawabe, S.; Shimokawa, T.; Miki, H.; Matsuda, S.; Endo, H. Variation in avian brain shape: Relationship with size and orbital shape. J. Anat. 2013, 223, 495-508. [CrossRef]

88. Weisbecker, V.; Rowe, T.; Wroe, S.; Macrini, T.E.; Garland, K.L.S.; Travouillon, K.J.; Black, K.; Archer, M.; Hand, S.J.; Berlin, J.C.; et al. Global elongation and high shape flexibility as an evolutionary hypothesis of accommodating mammalian brains into skulls. Evolution 2021, 75, 625-640. [CrossRef]

89. Benson, R.B.J.; Starmer-Jones, E.; Close, R.A.; Walsh, S.A. Comparative analysis of vestibular ecomorphology in birds. J. Anat. 2017, 231, 990-1018. [CrossRef] [PubMed]

90. Isler, K.; van Shaik, C. Costs of encephalization: The energy trade-off hypothesis tested on birds. J. Hum. Evol. 2006, 51, 228-243. [CrossRef] [PubMed]

91. Wright, N.A.; Steadman, D.W.; Witt, C.C. Predictable evolution toward flightlessness in volant island birds. Proc. Natl. Acad. Sci. USA 2016, 113, 4765-4770. [CrossRef] [PubMed]

92. Li, H.; Sinha, A.; André, A.A.; Spötl, C.; Vonhof, H.B.; Meunier, A.; Kathayat, G.; Duan, P.; Voarintsoa, N.R.G.; Ning, Y.; et al. A multimillenial climatic context for the megafaunal extinctions in Madagascar and Mascarene Islands. Sci. Adv. 2020, 6, 42. [CrossRef] [PubMed] 